Research Article

\title{
Buffering Performance of High-Speed Impact Space Penetrator with Foam-Filled Thin-Walled Structure
}

\author{
Haitao Luo $\mathbb{D}^{1,2}$ Yuxin Li ${ }^{10},,^{3}$ Guangming Liu $\mathbb{D}^{1,2}$ Changshuai Yu, ${ }^{1,2}$ and Shipeng Chen ${ }^{3}$ \\ ${ }^{1}$ State Key Laboratory of Robotics, Shenyang Institute of Automation, Chinese Academy of Sciences, Shenyang 110016, China \\ ${ }^{2}$ Institutes for Robotics and Intelligent Manufacturing, Chinese Academy of Sciences, Shenyang 110016, China \\ ${ }^{3}$ Institute of Mechanical Engineering and Automation, Northeastern University, Shenyang 110819, Liaoning, China
}

Correspondence should be addressed to Haitao Luo; luohaitao@sia.cn

Received 25 May 2019; Revised 16 September 2019; Accepted 7 November 2019; Published 26 November 2019

Academic Editor: Cristina Castejón

Copyright (c) 2019 Haitao Luo et al. This is an open access article distributed under the Creative Commons Attribution License, which permits unrestricted use, distribution, and reproduction in any medium, provided the original work is properly cited.

High-speed penetrators carrying detection equipment impact planetary bodies at high speeds, and they are therefore buried at depths of up to several meters beneath the surface. During the friction and collision with the crust of the planet, the acceleration of the scientific instrumentation is significantly large. The vibration protection structure for scientific instrumentation is necessary for the reduction of the peak value of the acceleration response and the improvement of the survival rate. In this study, a penetrator with a multilayered energy absorbing structure was developed to improve the survival rate of the penetrator, of which the foam-filled thin-walled structure (FTS) was applied to the penetrating vibration-damping structure. The penetration process of the penetrator into the planetary medium was simulated using the LS-DYNA software platform. The results obtained using empirical formulas and theoretical derivations were compared with the results of the numerical analysis. The reliability of the penetrator limit element model was then verified by conducting an impulse response experiment and simulation. The results suggest that FTS has a positive influence on the isolation impact and energy absorption. Moreover, the vibration isolation effects of nine different FTSs were evaluated with respect to the following six factors: impact isolation efficiency, load efficiency, peak of acceleration, peak impact force, total energy absorption, and specific energy absorption. Furthermore, the design of the damping structure provides an indispensable solution for penetrator detection.

\section{Introduction}

Deep-space exploration involves the detection of Solar System, Milky Way, and outer space [1-3]. To better understand Earth, Solar System, and the universe, various research institutions $[4,5]$ have directed significant research attention toward the improvement of deep-space detection technology. Research on penetration detection was first carried out in the previous century. This form of detection involves more detailed and comprehensive scientific data with a lower detection cost. In particular, for several minor celestial bodies such as Moon and Europa, the detection equipment is difficult to land, which increases the complexity of the detection task and costs. Therefore, it is necessary to conduct in-depth research on the penetrator, for successful adaptation to future deep-space exploration tasks. There are various types of penetrators that carry different payloads, such as heat flow probes, accelerometers, magnetometers, and communication modules. Commonly used penetrators include Mars 96 (Russia), Deep Space 2 (US), Lunar-A (Japan), and MoonLITE (the United Kingdom).

The penetrator is accompanied by strong vibrations and impacts during operation, which result in the high peak acceleration of the onboard scientific instrumentation (modern electronics), which are very sensitive to acceleration. In such a harsh environment, modern electronics are easily damaged. Therefore, protective design is essential for scientific instrumentation, in addition to the optimization of the vibration-damping performance of the protective 
structure. The main research directions include penetration performance, material and structure of the penetrator, and vibration reduction methods.

The foam-filled thin-walled structure (FTS) is a widely used vibration-damping structure. Dirgantara et al. [6] described the collisional mechanical properties of foamfilled single-wall and double-wall columns. The interaction between the foam core and the column wall changes the deformation mode from one partial fold to multiple propagation folds. Ebrahimi et al. [7, 8] studied the crashworthiness of functionally graded foam-filled tubes and analyzed the foamed aluminum density with respect to total energy absorption and the influence of the peak collision force. Fang et al. [9] developed square and hexagonal crosssectional foams. The thin-wall collision experiment was characterized by a progressive folding deformation mode, and the contribution of the number of pleats to the energy loss was studied. Yin et al. [10,11] numerically simulated the energy absorption characteristics of foam-filled multiunit thin-walled structures. The optimal optimization structure was determined by the multiobjective optimization function of the specific energy absorption and the peak force of the members.

\section{Materials and Methods}

\subsection{Kinematic Analysis}

2.1.1. Working Principle of Penetrator. After the penetrator is separated from the orbiter in the descending orbit and cruises to the nearest point to the planet, the braking of the rocket ignition forces the penetrator to continuously decelerate. The brake rocket is then separated from the penetrator, and the penetrator continuously descends. Under the control system and gravity, the angle of flight attack should be small, which reduces the contact resistance between the penetrator and the subsurface of the planet, thus obtaining the ideal depth of dive. The penetrator is then separated, and it descends from the orbiter. The schematic diagram of the landing process is shown in Figure 1.

The scientific instrumentation inside the penetrator can detect the temperature, magnetic field, seismic wave, and other scientific objects of the celestial body. Then the detected information will be transmitted to Earth after being received by the satellite $[12,13]$.

2.1.2. Design of Penetrator. In this paper, a penetrator is designed as the research object, and the FTS is applied to the protective design of the penetrator. The detailed structure of the penetrator is shown in Figure 2.

The main components of the penetrator are an external protection structure and an FTS, as shown in Figure 3, in addition to scientific instrumentation, a damping layer, and a damping spring. The scientific instrumentation includes the detection device and its power module. The external protection structure is a critical protective structure for penetration protection, as it isolates the penetrating medium from the internal structure. It is the part under the most

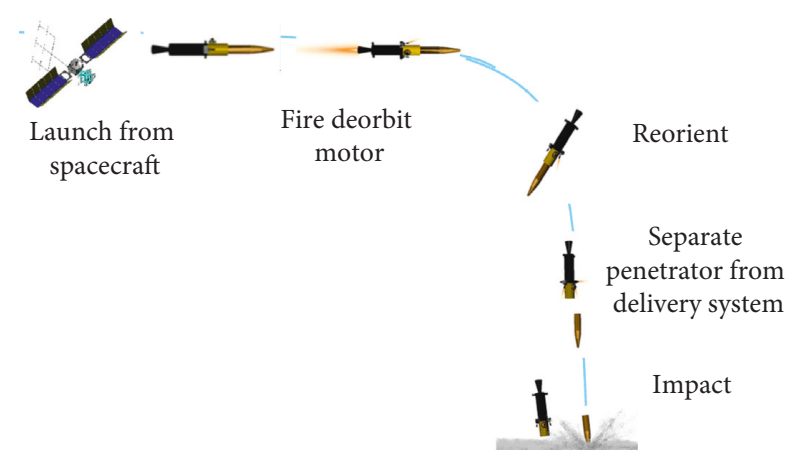

FIGURE 1: Working principle of the high-speed impact penetrator.

significant amount of stress. The FTS, which acts as a protective buffer during collision and penetration, is critical to the continued functionality of the onboard scientific instrumentation [14].

2.1.3. Young's Formula. At present, the research methods of projectile penetration exhibit a diversified trend. The main methods are the empirical method, theoretical method, and the numerical analysis method. The empirical method (Young's formula) and theory analysis method (Forrestal's formula) can be employed for the prediction of the numerical analysis results.

Researchers in the United States of America summarized the experimental data into an empirical formula referred to as Young's formula [15], which is a classic formula for projectile penetration into soil, rock, and concrete media, to calculate the penetration depth. In the engineering calculation of the soil penetration, it is still widely used. The specific calculation method can be expressed as follows:

$$
P=0.0008 S N\left(\frac{m}{A}\right)^{0.7}(v-30.5),
$$

where $m$ is the mass of the penetrator; $A$ is the cross-sectional area of the penetrator; $v$ is the landing speed; $N$ is the shape coefficient of the penetrator; and $S$ is the index of penetrability, which is related to the hardness of the soil. The coefficient of elasticity is as follows:

$$
N=\frac{0.18 h}{2 a}+0.56
$$

where $h$ is the length of the projectile and $2 a$ is the diameter of the projectile. In this study, $N=0.83$. The penetration index can be expressed as follows:

$$
S=20.1-\frac{4 E_{a}}{3}
$$

where $E_{a}$ is the constrained modulus of the soil.

It can be seen from equations (1)-(3) that the penetration depth of the penetrator can be predicted using the shape parameters, in addition to the mass and soil parameters of the penetrator. However, Young's formula has significant limitations, in which a detailed analysis of the physical quantities such as the velocity and acceleration of the penetrator cannot be conducted. 


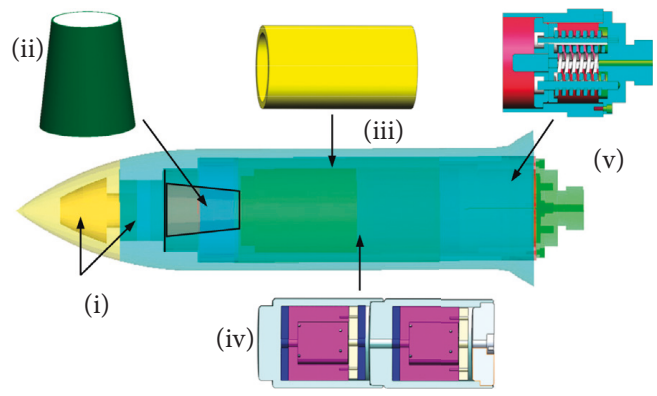

(a)

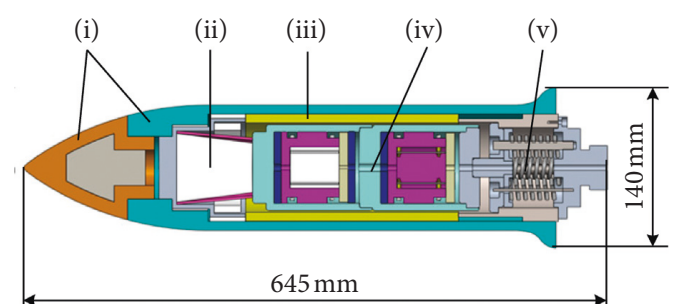

(b)

FIgURE 2: (a) Structural composition of the penetrator; (b) profile of the penetrator. (i) External protection structure, (ii) FTS, (iii) damping layer, (iv) scientific instrumentation, and (iv) damping spring.

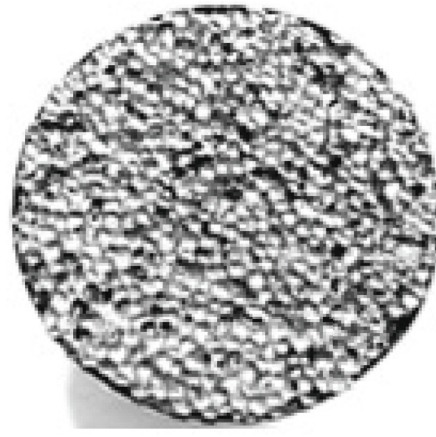

(a)

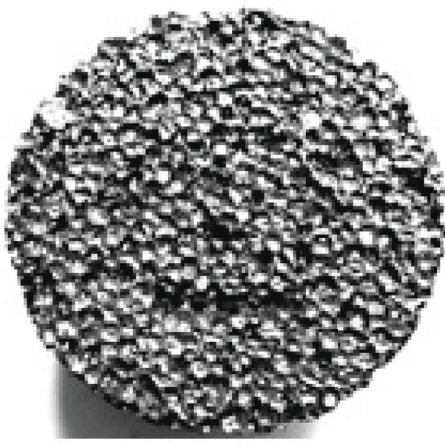

(b)

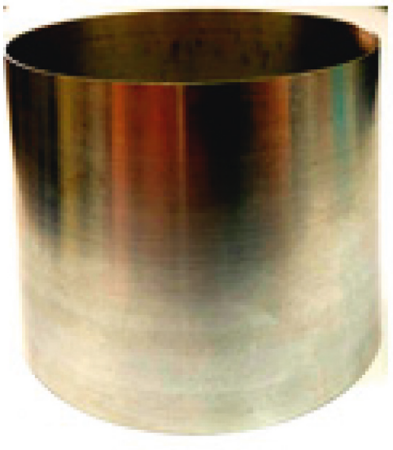

(c)

Figure 3: Foam-filled thin-walled structure. (a) FTS, (b) aluminum foam, and (c) thin wall.

2.1.4. Forrestal's Formula. Luk et al. $[16,17]$ applied the cavity expansion theory to the penetrator that penetrates the soil medium and then obtained the normal stress on the surface of the penetrator during the penetration process:

$$
\sigma_{n}=\tau_{0} \mathrm{~A}+\rho_{0} \mathrm{~B} v_{n}^{2},
$$

where $\mathrm{A}$ and $\mathrm{B}$ are the material constants determined by the cavity expansion theory and $\tau_{0}$ and $\rho_{0}$ are the Tresca yield stress and initial density of the soil medium, respectively. Moreover, $v_{n}$ is the cavity expansion velocity, i.e., the normal velocity of the projectile surface.

The penetration depth of the limit can be expressed as follows:

$$
P=\frac{m}{2 \beta_{s}} \ln \left[1+\frac{\beta_{s} v_{0}^{2}}{\alpha_{s}}\right]
$$

where $P$ is the limit depth, $m$ is the total mass, $\alpha_{s}$ and $\beta_{s}$ are the penetration parameters, and $v_{0}$ is the landing speed.

The empirical formula and the theoretical derivation method can only be used to study the penetrating performance. The research on the impact isolation effect can be easily determined using a numerical simulation [18-20].

\subsection{Numerical Simulation}

2.2.1. Penetration Model. The penetrator model was modeled in Hypermesh/LS-DYNA to obtain the finite element model shown in Figure 4. The contact between the outer protective shell and the soil medium was defined by the ERODING_SURFACE_TO_SURFACE contact type, the contact type between the internal scientific instrumentations was defined by the AUTOMATIC_ SURFACE _TO_SURFACE contact type, and the friction coefficient was set as 0.1 [21-25]. The thin-walled material was aluminum alloy AA6060-T4, and the filling material was aluminum foam. A hexahedral element was used to divide the soil target into grids. The element size of the soil was set as $30 \mathrm{~mm}$, thus totaling $1,188,000$ elements. The whole model consists of $1,366,100$ elements and 1,467,944 nodes.

2.2.2. Material Modeling. The material parameters of each part of the penetrator can be described as follows:

(1) Aluminum Foam. The hardening equation of aluminum foam [26] is a function of yield stress, plateau stress, and equivalent strain, which can be expressed as follows: 

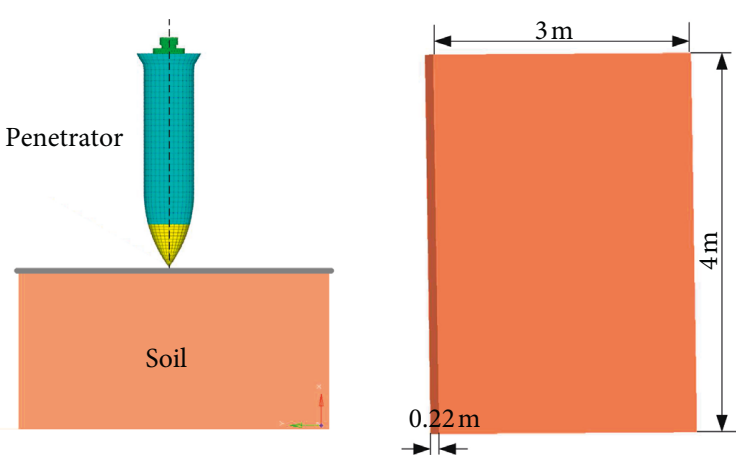

FIgURE 4: FE model.

$$
\sigma_{y}=\sigma_{p}+\gamma \frac{\widehat{\mathcal{\varepsilon}}}{\varepsilon_{D}}+\alpha_{2} \ln \left[\frac{1}{1-\left(\widehat{\mathcal{\varepsilon}} / \varepsilon_{D}\right)^{\beta}}\right],
$$

where $\alpha_{2}, \beta$, and $\gamma$ are the material parameters; $\widehat{\varepsilon}$ is the equivalent strain; $\sigma_{y}$ is the yield stress; $\sigma_{p}$ is the platform stress; and $\varepsilon_{D}$ is the compact equivalent strain, which is related to the density of the foamed aluminum:

$$
\varepsilon_{D}=-\frac{9+\alpha^{2}}{3 \alpha^{2}} \ln \left(\frac{\rho_{f}}{\rho_{f 0}}\right)
$$

where $\rho_{f}$ is the density of aluminum foam; $\rho_{f 0}$ is the density of the foamed aluminum-based material; $v^{p}$ is the plastic Poisson's ratio; and $\alpha$ is the material parameter, which is related to the compressive deformation volume and deformation form.

The equivalent strain $\widehat{\mathcal{E}}$ is calculated as follows:

$$
\widehat{\varepsilon}=\frac{\sqrt{1+(\alpha / 3)^{2}}}{\alpha} \frac{\left|\varepsilon_{m}\right|}{\sqrt{1-\left(1+(\alpha / 3)^{2}\right)\left(\chi^{*}\right)^{2}}}
$$

where the strain path parameter $\chi^{*}=1$. Moreover, the detailed material parameters of aluminum foam specimens with different densities are shown in Table 1.

(2) Aluminum Thin Wall. The tapered thin-walled structure is shown in Figure 5, in which the half of the taper angle is $5^{\circ}$. The material was AA6060-T4, the modulus of elasticity was $64.86 \mathrm{GPa}$, Poisson's ratio was 0.28 , the yield strength was $71 \mathrm{MPa}$, and the ultimate stress was $164 \mathrm{MPa}$. The engineering stress-strain curve of the material is shown in Figure 6.

(3) Soil. The soil model was a cuboid with dimensions of $3 \mathrm{~m} \times 4 \mathrm{~m} \times 0.22 \mathrm{~m}$ to ensure that the penetrator stops. The deformation of soil was modeled using the MAT-147 MAT_FHWA_SOIL model on the LS-DYNA software platform. The model surface was a modified Mohr-Coulomb surface to determine the pressure-dependent peak shear strength. The specific parameters of the model are shown in Table 2.

(4) Others. The material of the external protection structure of the penetrator is alloy steel, and the material of the
TABLE 1: Material parameters of aluminum foam with different densities [27, 28].

\begin{tabular}{lcccccc}
\hline$\rho_{f}\left(\mathrm{~g} / \mathrm{cm}^{3}\right)$ & $E(\mathrm{MPa})$ & $\gamma(\mathrm{MPa})$ & $\varepsilon_{D}$ & $\alpha_{2}(\mathrm{MPa})$ & $\beta$ & $\sigma_{p}(\mathrm{MPa})$ \\
\hline 0.17 & 377 & 1.87 & 2.77 & 93.5 & 5.79 & 1.15 \\
0.35 & 2211 & 2.3 & 2.1 & 60.2 & 4.20 & 6.2 \\
0.51 & 5562 & 5.37 & 1.67 & 66.9 & 2.99 & 14.82 \\
\hline
\end{tabular}
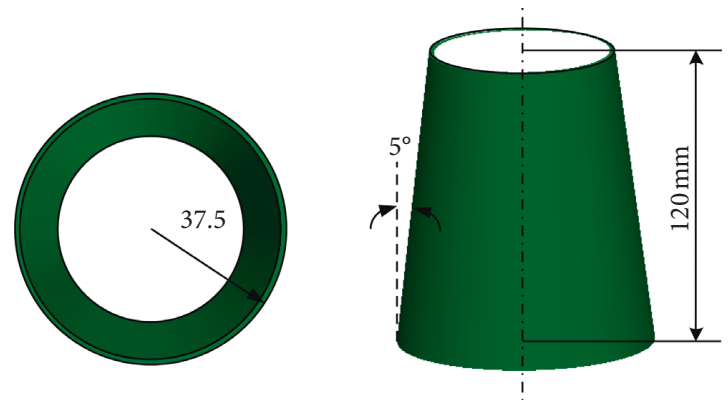

FIGURE 5: Geometric features of FTS.

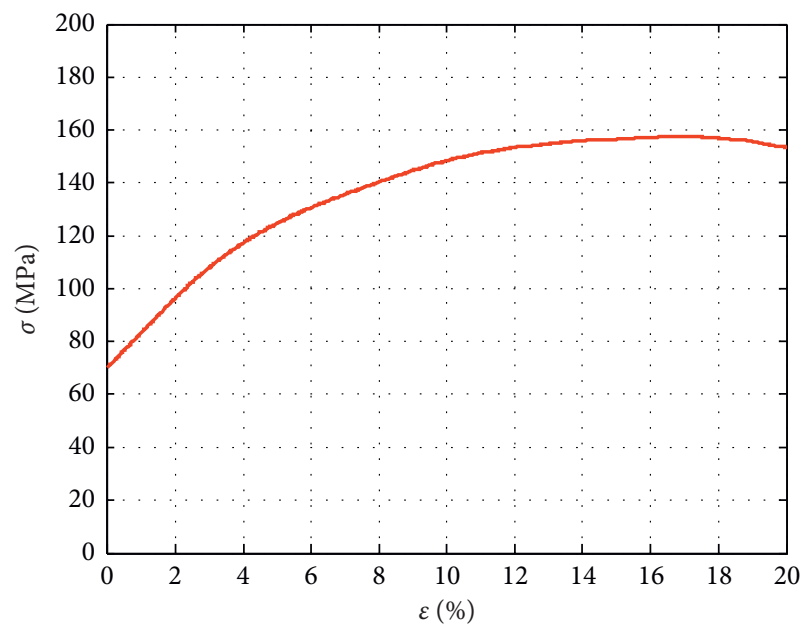

FIgURE 6: Stress-strain curve of AA6060-T4.

TABLE 2: Material parameters of soil.

\begin{tabular}{lcccc}
\hline$\rho\left(t / \mathrm{mm}^{3}\right)$ & $K(\mathrm{MPa})$ & $G(\mathrm{MPa})$ & DAMLEV & EPSMAX \\
\hline $2.4 e-9$ & 35 & 1.87 & 0.5 & 0.5 \\
\hline
\end{tabular}

$K$ is the bulk modulus, $G$ is the shear modulus, DAMLEV represents the level of damage that results in element deletion, and the EPSMAX is the maximum principle failure strain.

scientific instrument is aluminum alloy 7075. The material of the damping layer is polyurethane. The material properties are shown in Table 3.

\section{Results and Discussion}

\subsection{Validation of Numerical Models}

3.1.1. Shock Response Experiment. The experimental results validated the reliability of the numerical analysis results. Due to the complexity of the penetrator penetration 
TABLE 3: Material properties.

\begin{tabular}{lccccc}
\hline Material & $E(\mathrm{MPa})$ & $\mu$ & $\rho\left(t / \mathrm{mm}^{3}\right)$ & $G(\mathrm{MPa})$ & $\beta$ \\
\hline Alloy steel & $2.1 e 5$ & 0.28 & $7.7 e-9$ & - & - \\
7075 & $7.2 e 4$ & 0.33 & $2.8 e-9$ & 230 & - \\
Polyurethane & - & 0.45 & $1 e-8$ & 1.5 & 1.05 \\
\hline
\end{tabular}

experiment, significant preliminary preparation work was required. From the simulation results, the impact acceleration of the penetration process exceeded $10,000 \mathrm{~g}$. However, the maximum impact acceleration of the experimental equipment was only $3000 \mathrm{~g}$. Therefore, this experiment was only used as a verification of the reliability of the finite element model.

(1) Observation Points. The selection of two observation points was required during the test to facilitate the recording of the acceleration of the thin-walled structure and the FTS.

The selection of the observation points was carried out for a simple comparison between the data of the two observation points and to ensure that the sensor has a large attachment area (i.e., the sensor is firmly fixed during the impact test). The layout of the acceleration sensor is shown in Figure 7.

(2) Experimental Equipment and Impact Input. The penetrator and the resonance plate were fastened together using bolts, and the impact hammer was set up to strike the resonance plate after the pneumatic rod is pushed, as shown in Figure 8.

The input conditions of the impact test bench are shown in Figure 9. The peak value of the impact acceleration was set as $3000 \mathrm{~g}$ (in the frequency domain), and the rising slope was $6 \mathrm{db} /$ oct. The impact response spectrum test was conducted on a penetrator with thin wall thicknesses of $0.2 \mathrm{~mm}$, $0.3 \mathrm{~mm}$, and $0.4 \mathrm{~mm}$ and a foam-filled aluminum thin wall with a thickness of $0.2 \mathrm{~mm}$.

(3) Experimental Result. The deformation of the thin wall and FTS are shown in Figure 10. Given that the experimental input conditions of the four structural members were equal, the acceleration signals detected by using the acceleration sensor were similar in the time domain. The output result of one structural member is shown in Figure 11.

The acceleration was found to decay rapidly within $10 \mathrm{~ms}$, and the peak acceleration reached $4000 \mathrm{~g}$. This acceleration response was then used as an input to the numerical simulation analysis to obtain the acceleration response of the scientific instrumentation, i.e., the acceleration response of Point 2. The test response of Test Point 2 is presented with respect to the simulation results in Figure 12.

\subsubsection{Numerical Simulation of Shock Response Spectrum} Experiment. The finite element model is shown in Figure 13. The penetrator model in this model was the same as that in the penetration simulation. The acceleration signal of a point obtained by the test was inputted to the penetrator model along the direction of the penetrator axis. The simulated acceleration results were then compared with the test results to determine the accuracy of the response results [14].

\section{Results}

The deformation, which represents the length of the eroded above four structures along the axis direction, is shown in Figure 14. Table 4 presents a comparative data sheet for the simulation and experimental deformation, with a maximum error of $9.3 \%$.

The acceleration of Point 2 is shown in Figure 12. Although the damping effect of the FTS was the least significant, the error between the numerical simulation and experimental results was small. Moreover, under the condition of $10,000 \mathrm{~g}$, the numerical simulation results indicated that the impact absorption effect of the FTS improved and that the crushing of the thin wall would occur.

The results of the finite element analysis exhibited the same general trend as that of the test results. The time and peak size of the transient response were not significantly different, with an error of less than 9\%, as shown in Table 5. The results revealed that the finite element analysis results contained a reference value, thus validating the reliability of the finite element model established in this study.

\subsection{Simulation Results}

4.1.1. Penetration Collision Process. The penetration depth of the penetrator is related to the mission requirements, the type of payload and the initial velocity, among others. The penetrator was designed to penetrate the surface of the planet by a depth greater than $4 \mathrm{~m}$ for the detection of the subsurface composition and changes in temperature. The penetration process of the soil medium at different initial velocities was simulated in this study. The trajectory of the penetrator with an initial velocity of $150 \mathrm{~m} / \mathrm{s}$ in the soil is shown in Figure 15.

From Figure 16, it can be seen that the ultimate dive depth of the penetrator is related to the landing speed. When the landing speed is less than $280 \mathrm{~m} / \mathrm{s}$, the detection task is difficult to complete; thus, the landing speed of the selected penetrator was $300 \mathrm{~m} / \mathrm{s}$. In this study, the simulation results were compared with the results of the empirical method and the theory analysis method, as shown in Figure 17.

The results indicated that the trend of the changes in the calculation results of the theoretical method, empirical method, and simulation was the same, with an error of less than $5 \%$, which verifies the accuracy of the penetration model established in this study, in addition to the reliability of the results.

4.1.2. Evaluation of Buffering Effect. Due to the influence of the numerical analysis calculation error, the initial velocity $v=300 \mathrm{~m} / \mathrm{s}$ was set. In addition, 6060-T4 thin walls with thicknesses of $t=2.5 \mathrm{~mm}, 3 \mathrm{~mm}$, and $3.5 \mathrm{~mm}$, which had material densities of $0.17 \mathrm{~g} / \mathrm{cm}^{3}, 0.35 \mathrm{~g} / \mathrm{cm}^{3}$, and $0.51 \mathrm{~g} / \mathrm{cm}^{3}$, 


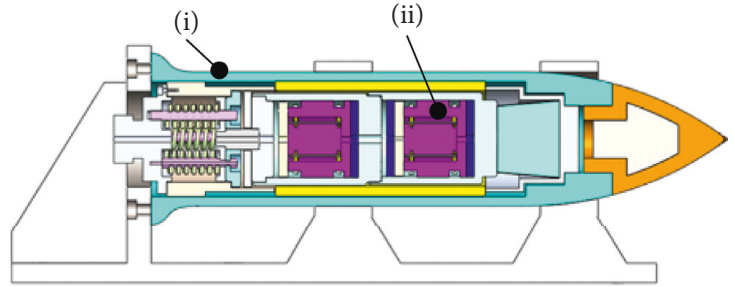

(a)

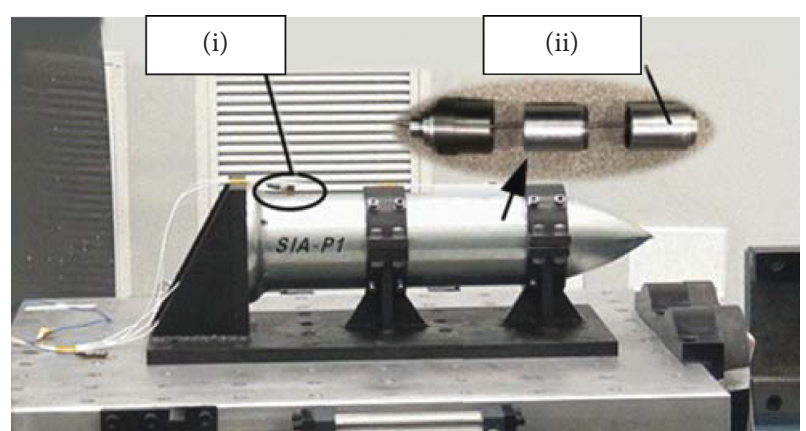

(b)

FiguRe 7: Distribution of sensor observation points. (a) Set position of the observation point; (b) observation point arrangement in the test. (i) Observation Point 1. (ii) Observation Point 2.

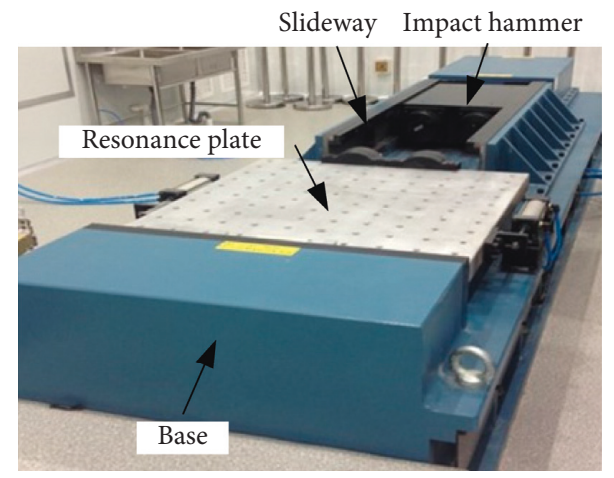

FIGURE 8: Shock spectrum response test device.

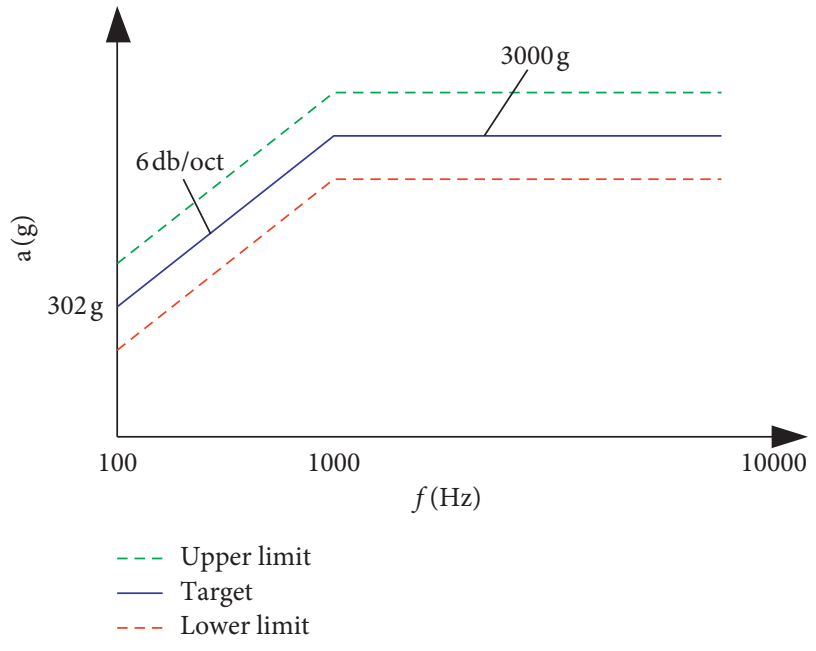

FIGURE 9: Test condition of the shock spectrum response test.

respectively, were selected for analysis. The deformation and energy absorption of the FTS with different density filling materials were studied. The acceleration produced by the landing resistance of a high-speed object allows for the object to withstand the impact of acceleration. The isolation system plays a role in reducing its maximum acceleration. Significant acceleration is the most critical indicator for the evaluation of the buffering performance of the high-speed impact penetrator.
(1) Acceleration Response. The vibration reduction effect of the FTS is directly reflected in the peak acceleration and the impact isolation efficiency of the internal load [29]. Moreover, it is possible to convert between the two parameters as follows:

$$
\eta=\frac{A_{n}-A_{m}}{A_{n}} \times 100 \%
$$

where $\eta$ is the impact isolation efficiency, $A_{m}$ is the peak of the impact acceleration response of scientific instrumentation, and $A_{n}$ is the peak of the impact acceleration response of the outer protective structure.

During the impact, the outer protective structure is first affected. The overload curve is shown in Figure 18(a). The maximum acceleration peak of the protective structure exceeded $10,000 \mathrm{~g}$. With an increase in the penetration depth, the acceleration amplitude rapidly decayed.

The acceleration-time curve for scientific instrumentations under FTS protection is shown in Figures 18(b)-18(d). It can be seen from the results that there were variations in the accelerated response curve of the scientific instrumentation. The magnitude of the variations reflects the isolation impact efficiency. With a decrease in the variation of the acceleration curve, there was an improvement in the buffer absorption effect. The instability of the acceleration is due to the fold within the thin wall and the compression deformation of the aluminum foam. The acceleration peaks of the S2.5A0.17 and S2.5A0.35 scientific 


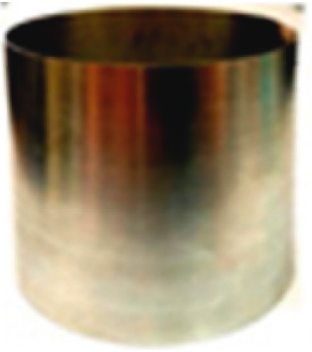

(a)

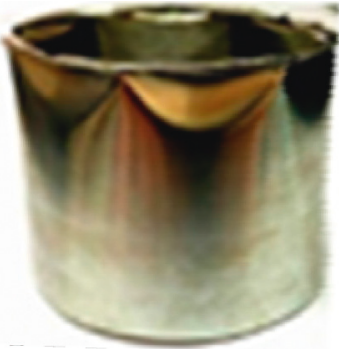

(b)

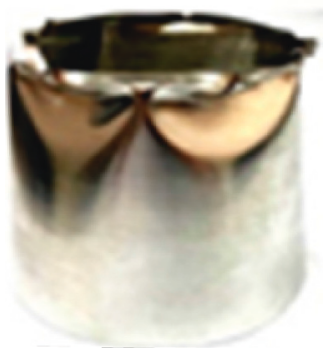

(c)

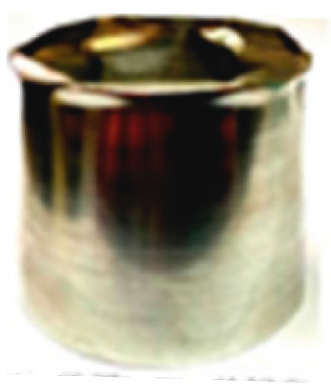

(d)

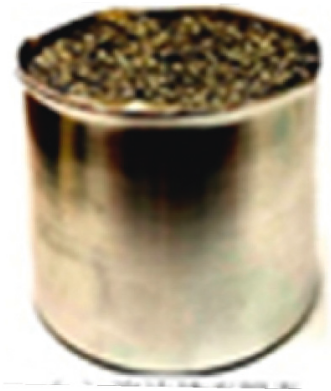

(e)

Figure 10: Deformation of experiment. (a) Before test, (b) thin wall with a thickness of 0.2 , (c) thin wall with a thickness of 0.3 mm (d), thin wall with a thickness of $0.4 \mathrm{~mm}$, and (e) FTS.

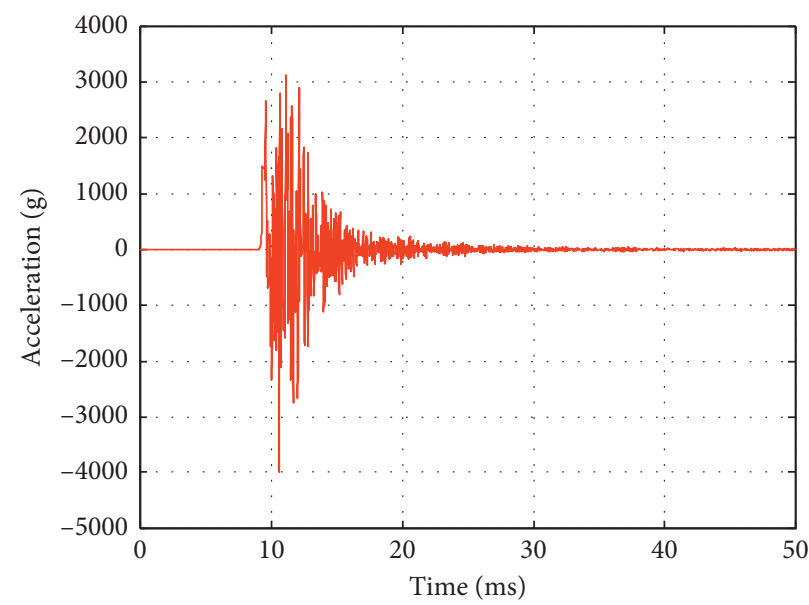

Figure 11: Acceleration response of the external protection structure.

instrumentations were excessively large, in addition to the variations, which is not a suitable design solution. For S2.5A0.51 and S3.0A0.35, the scientific instrumentation was found to have a stable acceleration and a minimum peak acceleration, which is suitable as a buffer structure.

The impact isolation efficiency of each structure is shown in Table 6. In addition, S2.5A0.51 was found to have the best barrier effect, with an impact isolation efficiency of $77.3 \%$. S2.5A0.17 demonstrated the least significant barrier effect, with an impact isolation efficiency of $27.4 \%$.

(2) Deformation of FTS. The deformation distance of the FTS represents the length of the eroded FTS along the axis direction. Aluminum foams of different densities and thin walls of different thicknesses were numbered in combination. The thin wall was labeled "S," and the aluminum foam was labeled “A.” For example, S3.0A0.35 represents the FTS with a thin wall thickness of $3.0 \mathrm{~mm}$ and the aluminum foam with a density of $0.35 \mathrm{~g} / \mathrm{cm}^{3}$. The deformation of each FTS is shown in Figure 19.

The upper end of the thin wall was in contact with the scientific instrumentation. Different types of deformation occur in the thin wall during impact. As shown in Figure 19, the thickness of the thin wall and the density of the aluminum foam have a significant influence on the impact deformation. With an increase in the density of the aluminum foam, the deformation distance (axial compression distance) of the FTS gradually decreased, for the same wall thickness. With an 


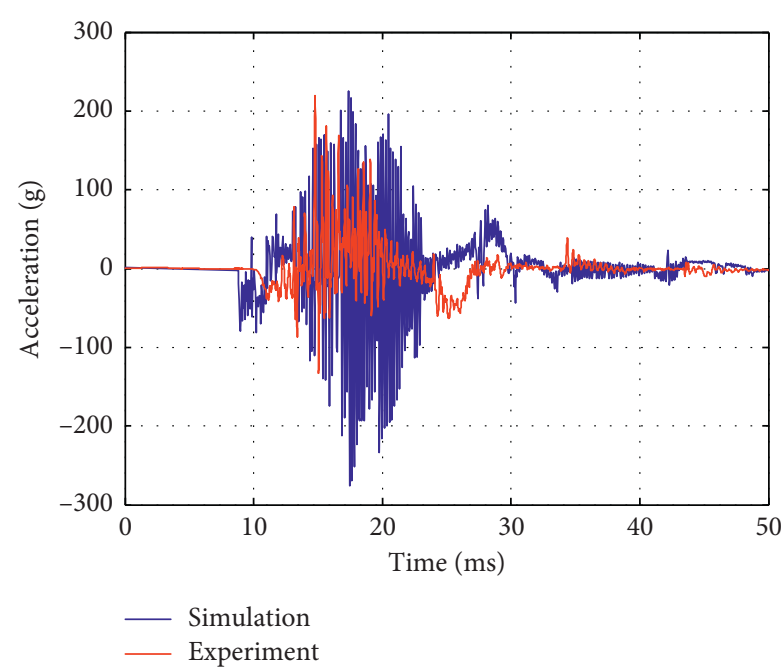

(a)

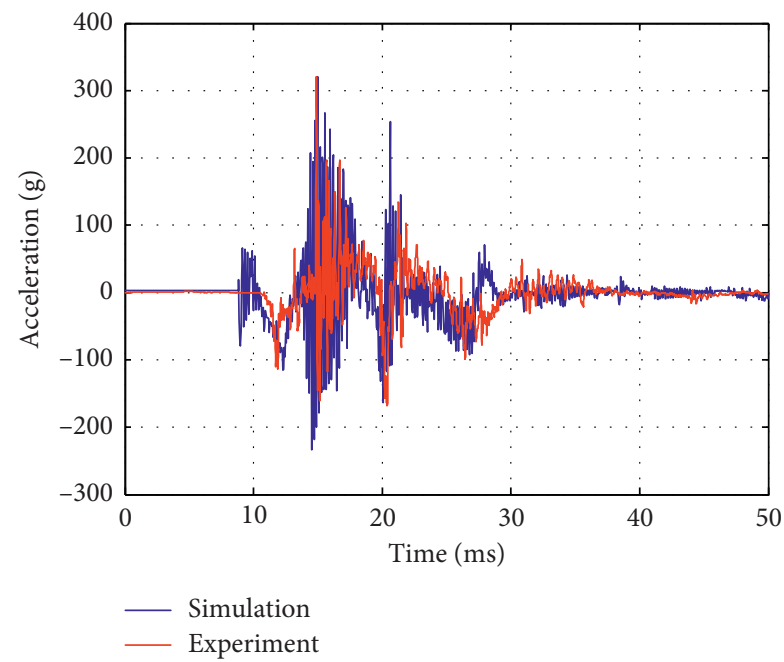

(c)

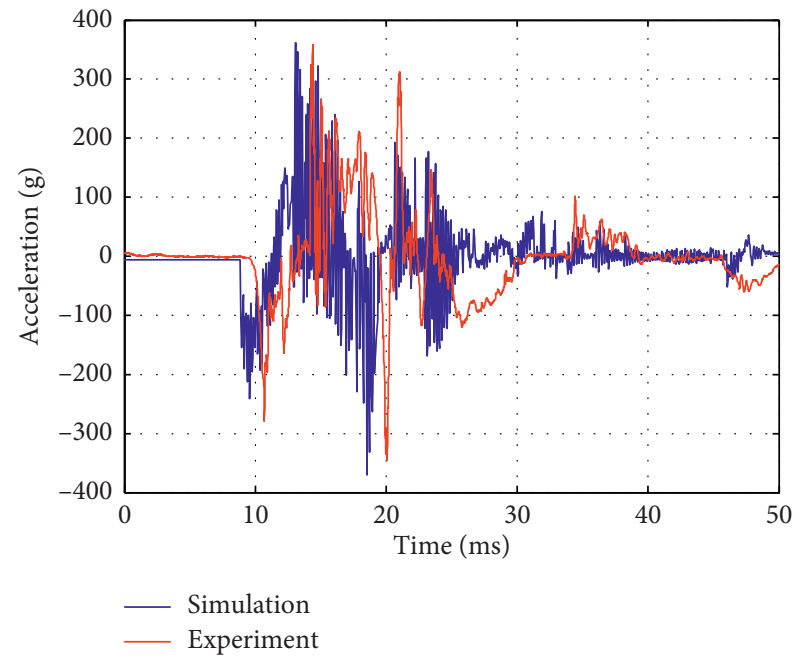

(b)

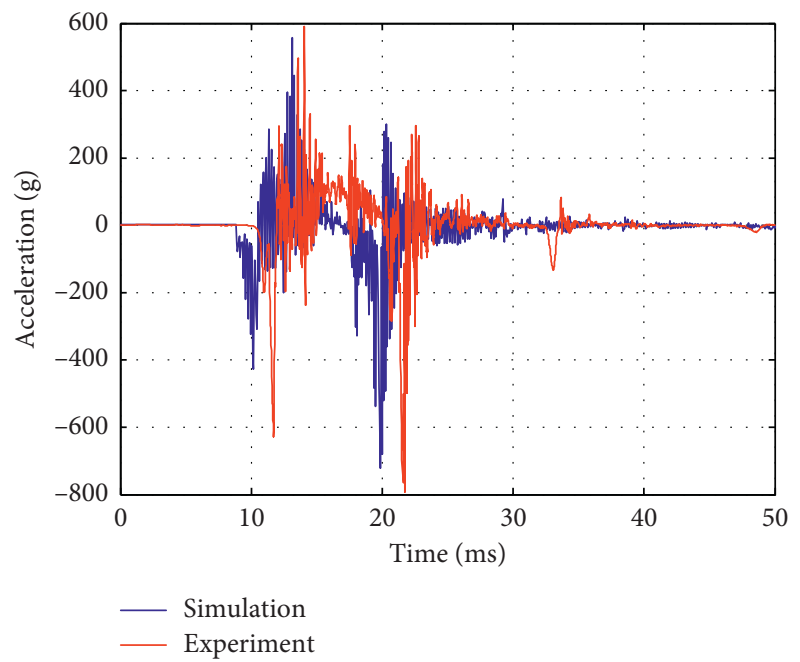

(d)

Figure 12: Acceleration response curves of test and simulation. (a) Thin wall with a thickness of $0.2 \mathrm{~mm}$, (b) thin wall with a thickness of $0.3 \mathrm{~mm}$, (c) thin wall with a thickness of $0.4 \mathrm{~mm}$, and (d) FTS with a thickness of $0.2 \mathrm{~mm}$.

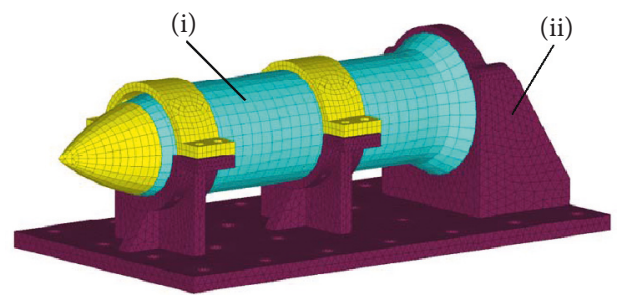

Figure 13: Finite element model. (i) Penetrator. (ii) Fixture.

increase in the wall thickness, the deformation distance of the FTS decreased, for the same aluminum foam density. To ensure the buffering energy absorption effect of the FTS, the structure is required to ensure a sufficient deformation distance without crushing. Figures 19(a) and 19(b) reveal that the thin wall was crushed. Figures 19(c)-19(f) reveal that the thin wall deformation was the most significant, by which buffering energy effect was realized. Figures 19(g)-19(i) reveal that the thin wall deformation was not significant; thus, the expected energy absorption effect was not realized. The deformation distance data are shown in Table 7. The analysis result revealed that S2.5A0.51 and S3.0A0.17 demonstrated an improved deformation distance, and it can therefore be used as an alternative.

(3) Crushing Force. The crushing force between the scientific instrumentation and the FTS can be evaluated using peak crushing force, average crushing force, and load efficiency. 


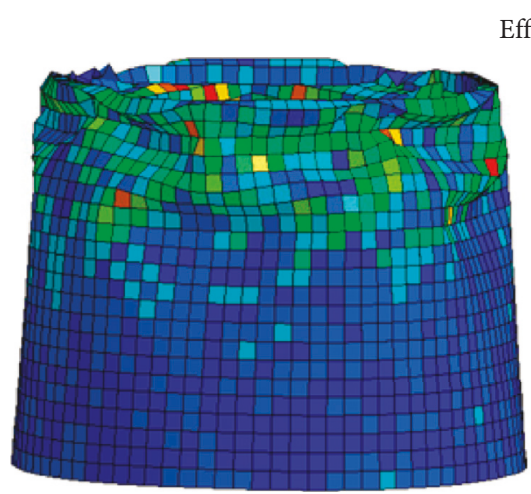

(a)

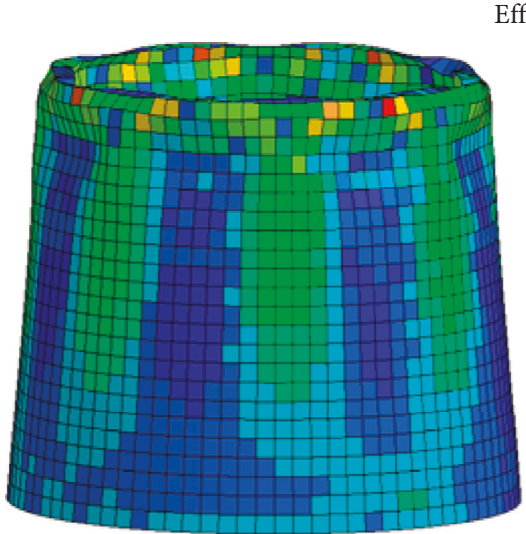

(c)

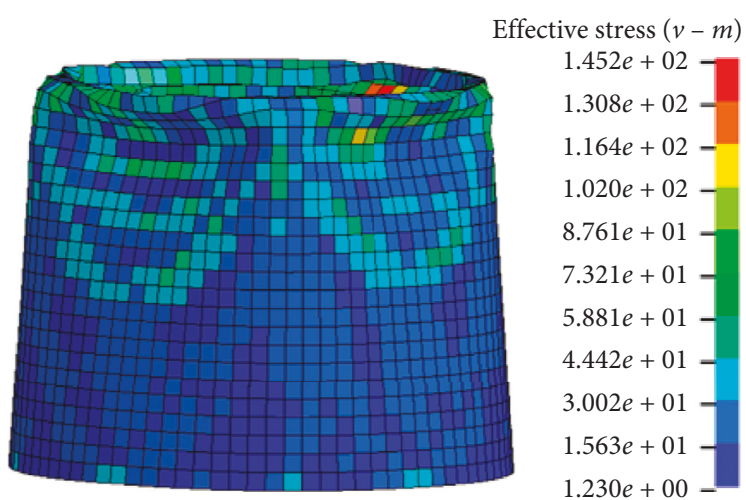

(b)

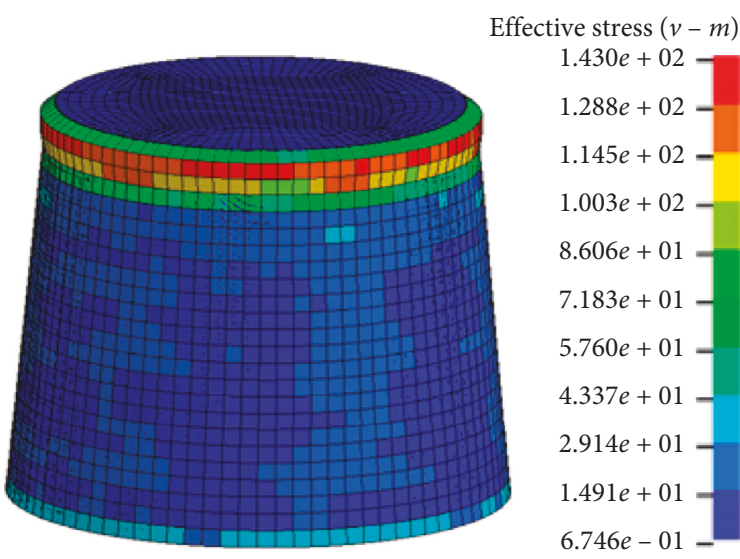

(d)

FIGURE 14: Deformation of simulation. (a) Thin wall with a thickness of $0.2 \mathrm{~mm}$, (b) thin wall with a thickness of $0.3 \mathrm{~mm}$, (c) thin wall with a thickness of $0.4 \mathrm{~mm}$, and (d) FTS.

TABle 4: Deformation data.

\begin{tabular}{lccc}
\hline Structure & Deformation of experiment $(\mathrm{mm})$ & Deformation of simulation $(\mathrm{mm})$ & Error $(\%)$ \\
\hline $0.2 \mathrm{~mm}$ thin wall & 10.6 & 10.0 & 6.0 \\
$0.3 \mathrm{~mm}$ thin wall & 8.4 & 7.9 & 6.3 \\
$0.4 \mathrm{~mm}$ thin wall & 5.3 & 5.1 & 3.9 \\
$0.2 \mathrm{~mm}$ FTS & 2.6 & 2.8 & 9.3 \\
\hline
\end{tabular}

TABLE 5: Peak acceleration of experiment and simulation.

\begin{tabular}{lccc}
\hline Structure & Acceleration of experiment $(\mathrm{g})$ & Acceleration of simulation $(\mathrm{g})$ & Error $(\%)$ \\
\hline $0.2 \mathrm{~mm}$ thin wall & 260 & 239 & 8.8 \\
$0.3 \mathrm{~mm}$ thin wall & 320 & 318 & 0.6 \\
$0.4 \mathrm{~mm}$ thin wall & 380 & 371 & 2.4 \\
$0.2 \mathrm{~mm}$ FTS & 721 & 789 & 8.6 \\
\hline
\end{tabular}

Under an axial load, the peak crushing force of the filled structure occurs at two moments of thin wall fold and foam aluminum compaction [30].

The total energy absorption is equal to the work of the deformation due to the crushing force:

$$
\mathrm{EA}=\int_{0}^{d} F d \delta
$$

where EA is the total energy absorption; $F$ is the crushing force; $\delta$ is the deformation distance, which is a function of time; and $d$ is the final deformation distance, which is the steady state value of $\delta$.

The average crushing force can be expressed as follows:

$$
F_{\text {avg }}=\frac{\mathrm{EA}}{d},
$$




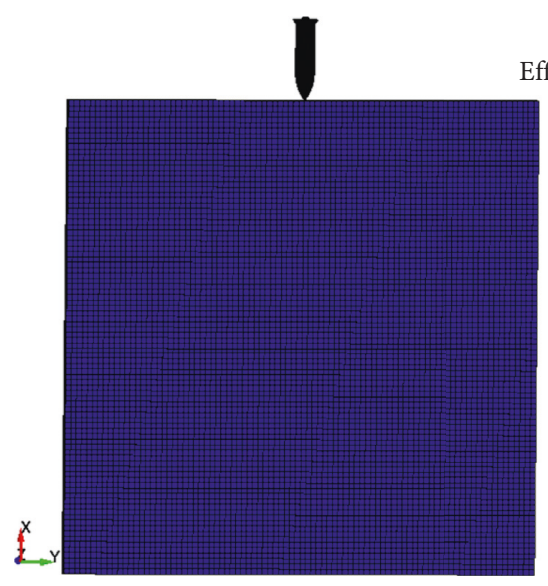

(a)

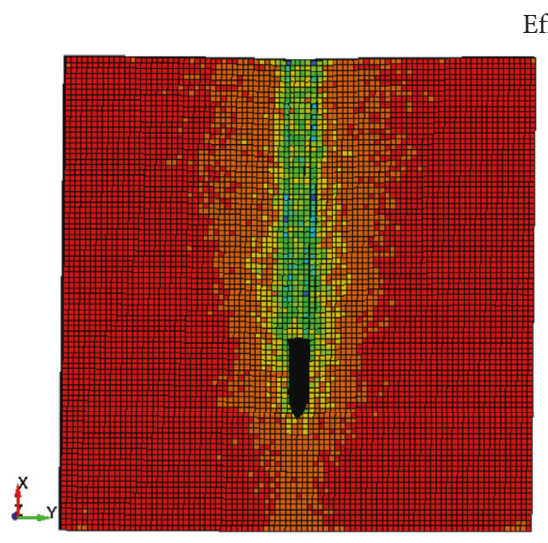

(c)
Effective stress $(v-m)$

$0.000 e+00-$
$0.000 e+00-$
$0.000 e+00-$
$0.000 e+00-$
$0.000 e+00-$
$0.000 e+00-$
$0.000 e+00-$
$0.000 e+00-$
$0.000 e+00-$
$0.000 e+00-$
$0.000 e+00-$

Effective stress $(v-m)$

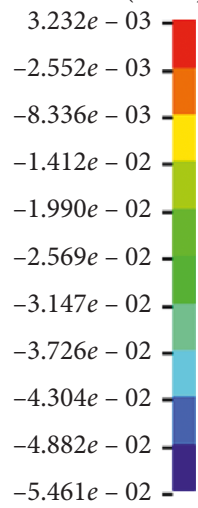

$-5.461 e-02=$

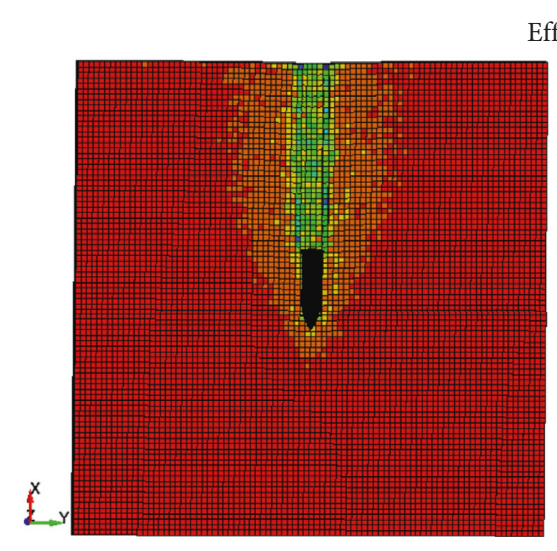

Effective stress $(v-m)$

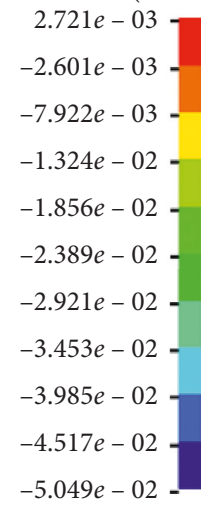

(b)

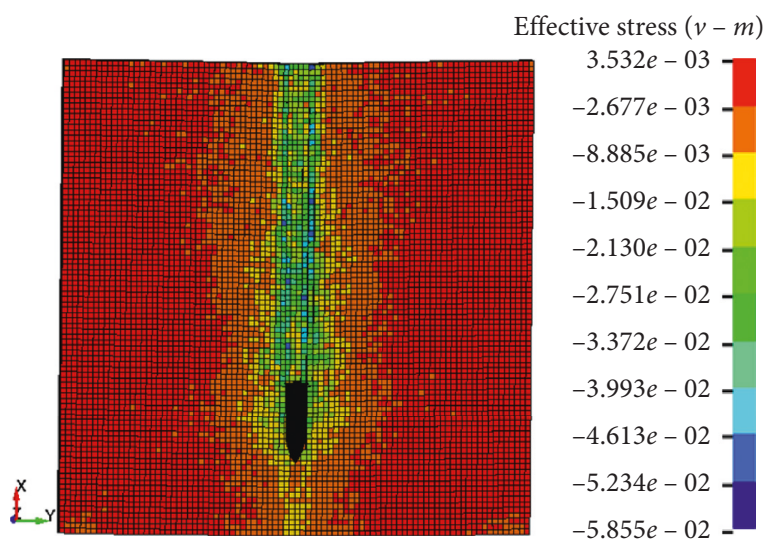

(d)

FIgURE 15: Motion trajectories at an initial speed of $150 \mathrm{~m} / \mathrm{s}$. (a) $t=0 \mathrm{~s}$, (b) $t=0.02 \mathrm{~s}$, (c) $t=0.04 \mathrm{~s}$, and (d) $t=0.08 \mathrm{~s}$.

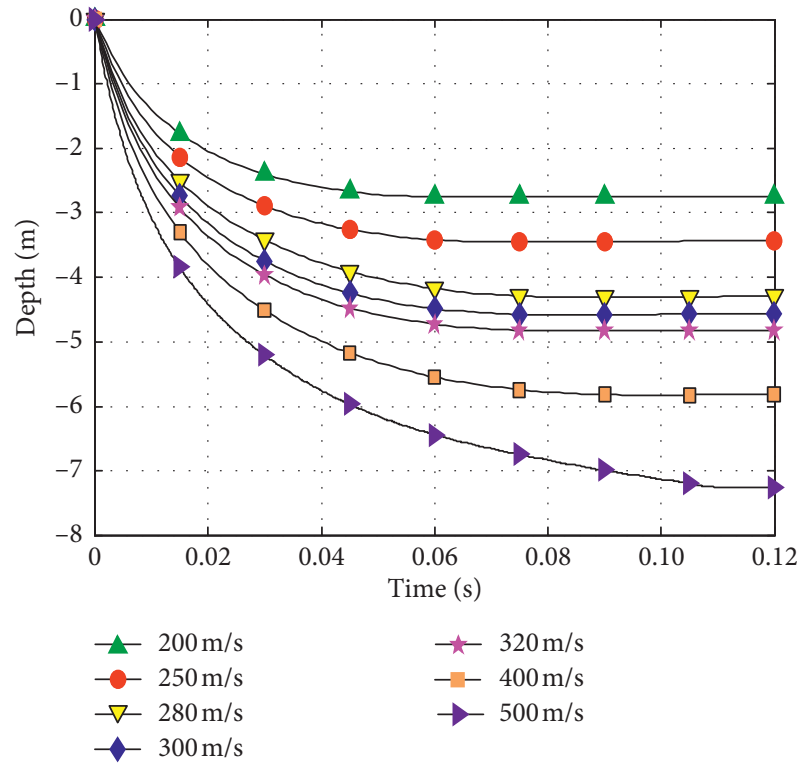

FIgURe 16: Penetration curves at different speeds.

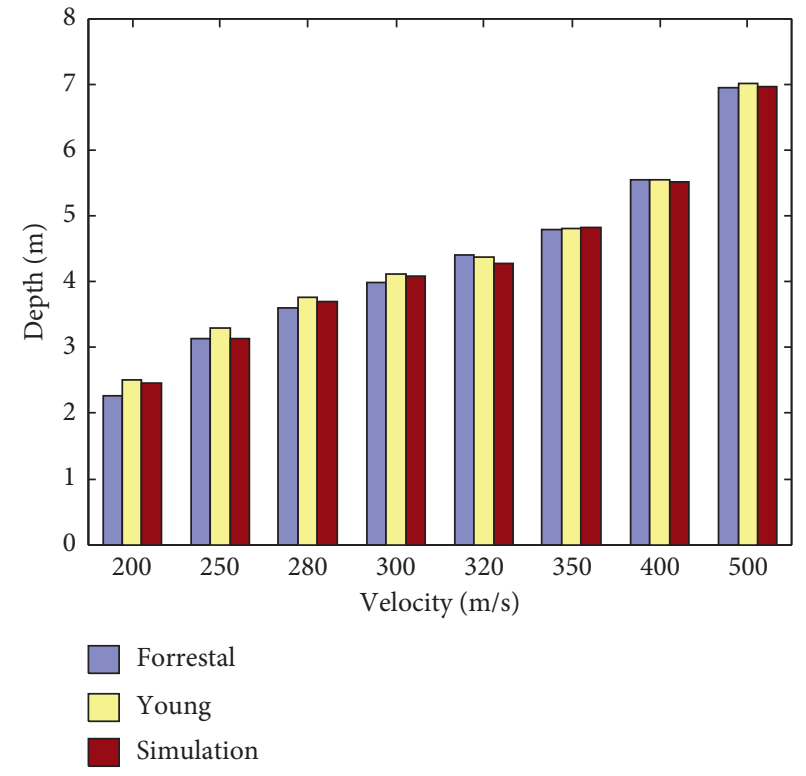

FIGURE 17: Histogram of error analysis. 

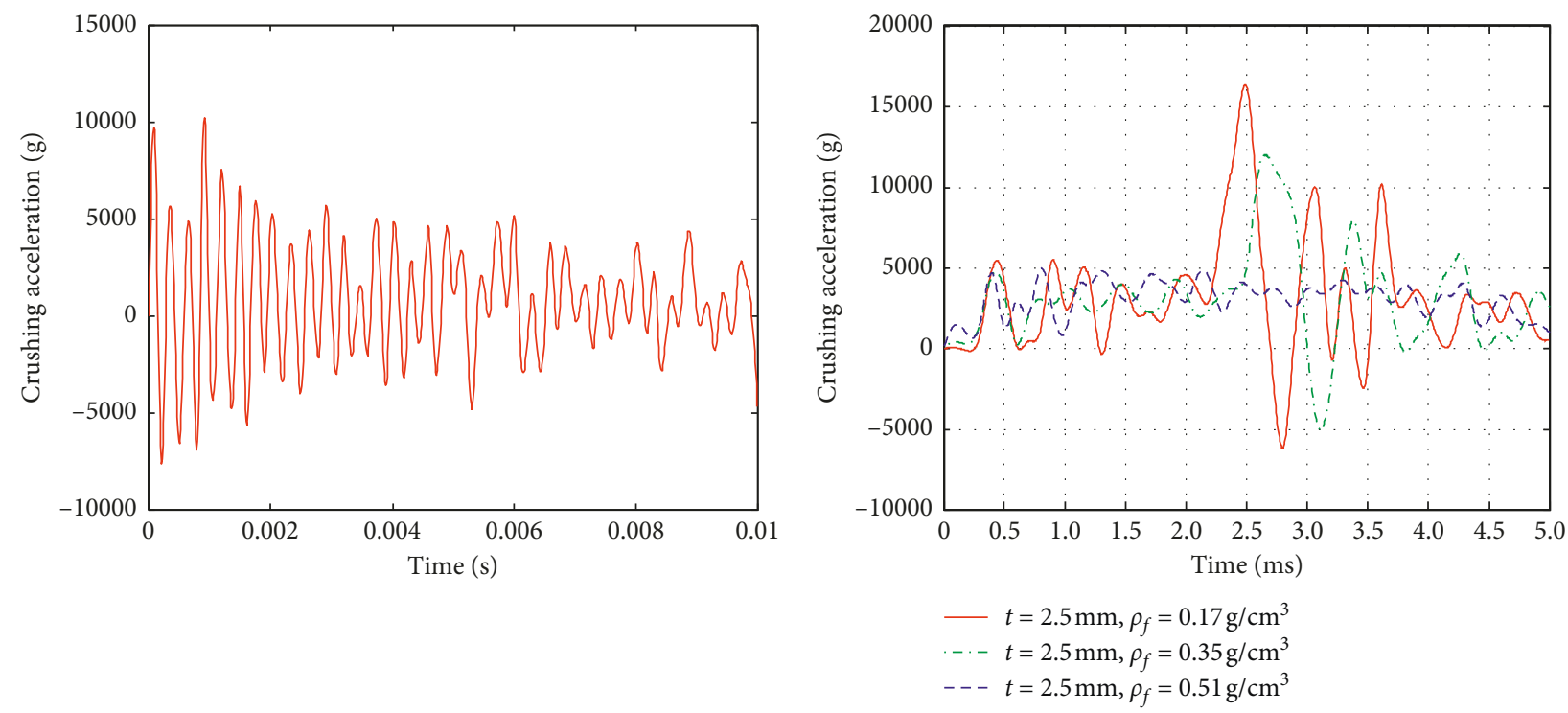

(a)

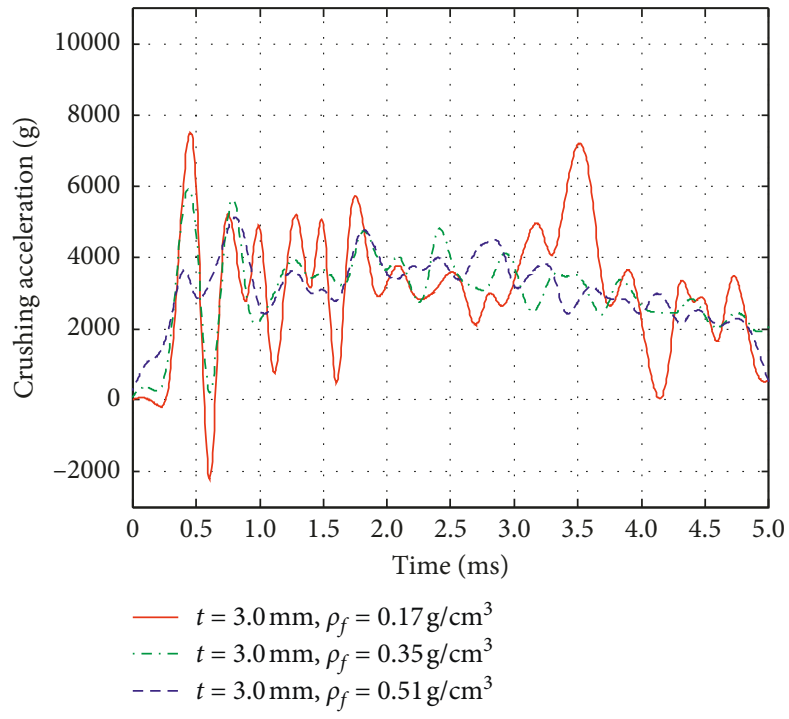

(c)

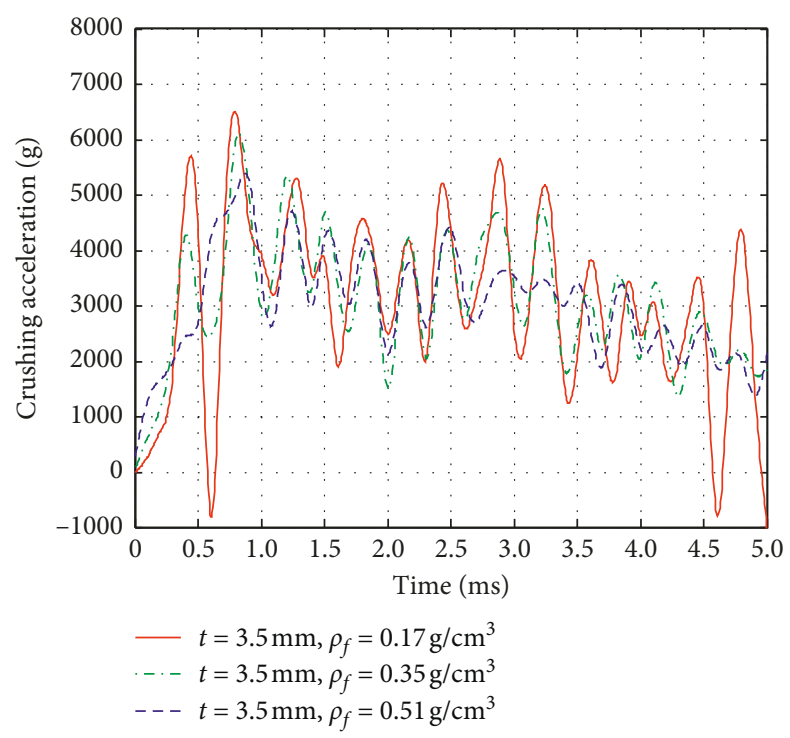

(d)

FIgURE 18: Acceleration-time curves. Acceleration response of (a) outer protective structure, (b) scientific instrumentations with a thickness of $2.5 \mathrm{~mm}$, (c) scientific instrumentations with a thickness of $3.0 \mathrm{~mm}$, and (d) scientific instrumentations with a thickness of $3.5 \mathrm{~mm}$.

TABLE 6: Impact isolation efficiency of FTS.

\begin{tabular}{lccc}
\hline FTS & $A_{n}(\mathrm{~g})$ & $A_{m}(\mathrm{~g})$ & $\eta(\%)$ \\
\hline S2.5A0.17 & 22700 & 16471 & 27.4 \\
S2.5A0.35 & 22700 & 12097 & 46.7 \\
S2.5A0.51 & 22700 & 5142 & 77.3 \\
S3.0A0.17 & 22700 & 7507 & 66.9 \\
S3.0A0.35 & 22700 & 5996 & 73.6 \\
S3.0A0.51 & 22700 & 5364 & 76.4 \\
S3.5A0.17 & 22700 & 6432 & 71.7 \\
S3.5A0.35 & 22700 & 6021 & 73.5 \\
S3.5A0.51 & 22700 & 5363 & 76.4 \\
\hline
\end{tabular}

where $F_{\text {avg }}$ is the average crushing force, which reflects the magnitude of the inertial force during the crushing, and it is related to the instance of the crushing.
The loading efficiency can be expressed as follows:

$$
\eta_{F}=\frac{F_{\text {avg }}}{F_{\max }},
$$

where $F_{\max }$ is the maximum crushing force.

The crushing force under different combinations is shown in Figure 20. The results indicated that there were significant variations in the impact forces of S2.5A0.17, S2.5A0.35, and S3.0A0.17 with large collision force peaks; and the load efficiencies were $40.3 \%, 40.6 \%$, and $47.1 \%$ with low energy absorption efficiencies. The collision force peaks of S2.5A0.51, S3.0A0.35, S3.0A0.51, S3.5A0.35, and S3.5A0.51 were approximately $200 \mathrm{kN}$, and the load efficiency exceeded $74 \%$, in which the energy absorption rate is better and is a suitable and efficient combination of the 


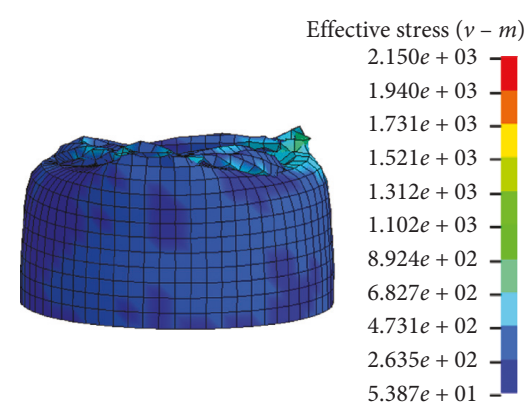

(a)

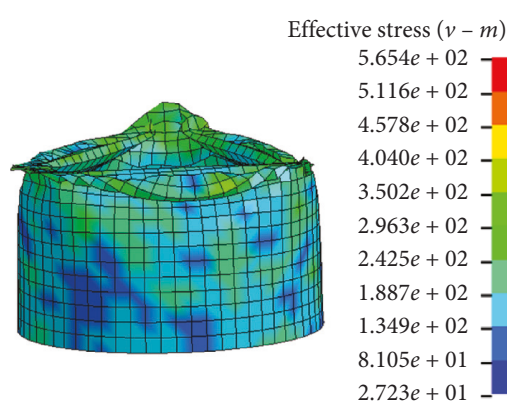

(d)

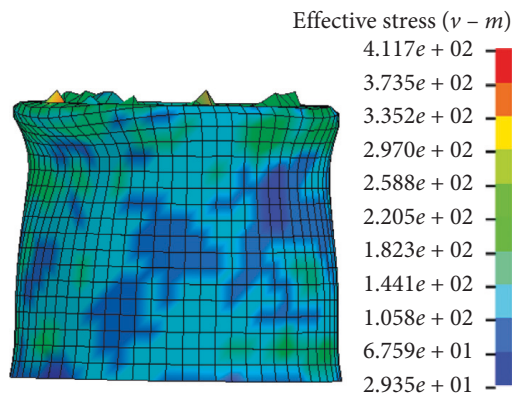

(g)

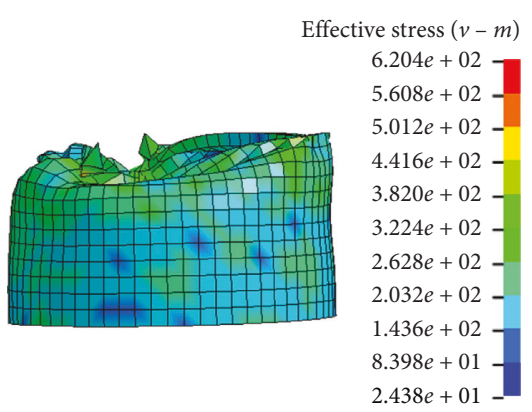

(b)

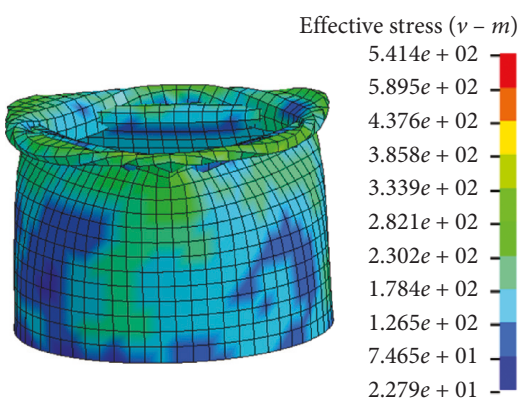

(e)

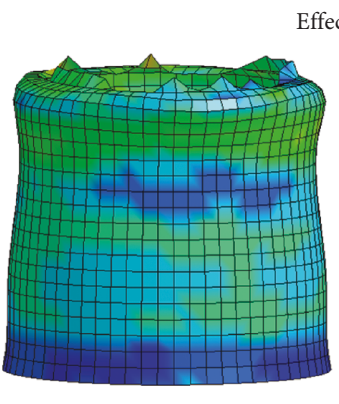

(h)

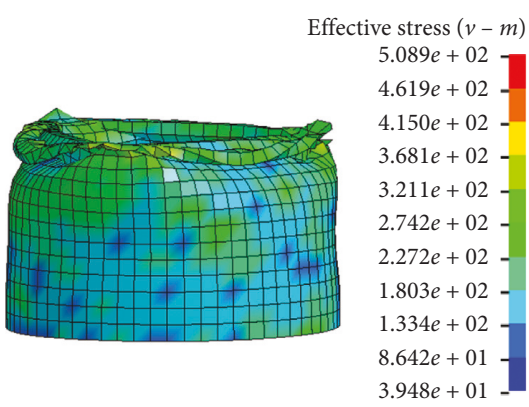

(c)

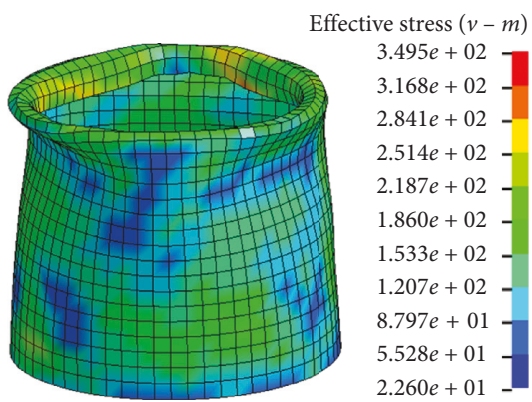

(f)

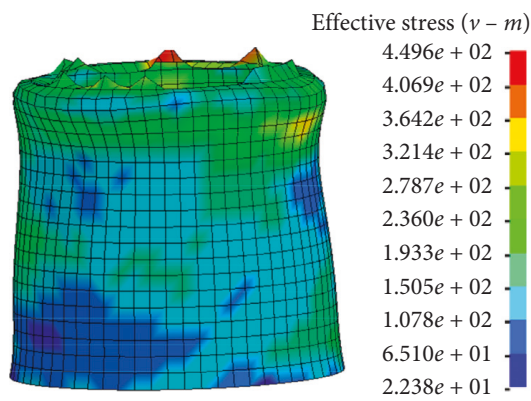

(i)

Figure 19: Deformations of FTS. (a) S2.5A0.17, (b) S2.5A0.35, (c) S2.5A0.51, (d) S3.0A0.17, (e) S3.0A0.35, (f) S3.0A0.51, (g) S3.5A0.17, (h) S3.5A0.35, and (i) S3.5A0.51.

TABLE 7: Deformation distance of FTS

\begin{tabular}{lcc}
\hline Number & FTS & Deformation $(\mathrm{mm})$ \\
\hline 1 & S2.5A0.17 & 52.34 \\
2 & S2.5A0.35 & 50.11 \\
3 & S2.5A0.51 & 43.35 \\
4 & S3.0A0.17 & 49.06 \\
5 & S3.0A0.35 & 41.19 \\
6 & S3.0A0.51 & 28.08 \\
7 & S3.5A0.17 & 16.87 \\
8 & S3.5A0.35 & 16.17 \\
9 & S3.5A0.51 & 10.67 \\
\hline
\end{tabular}

energy absorption structure. The load efficiency of the FTS is shown in Table 8.

(4) Specific Energy Absorption. In the optimization of the structural performance, it is preferable to achieve the desired goal with a smaller volume or quality. In this study, the specific energy absorption was used as an objective function of optimization. The specific energy absorption [31] is defined as follows:

$$
\mathrm{SEA}=\frac{\mathrm{EA}}{M},
$$

where SEA is the specific energy absorption, EA is the total energy absorption, and $M$ is the mass of the energy absorption structure.

In the range of the wall thickness and density of the foamfilled aluminum, the energy absorption and specific energy absorption of the structure exhibited a decreasing trend in accordance with an increase in the thickness and density. The results are shown in Figures 21 and 22. The absorption energy of the comparison of S2.5A0.17 and S2.5A0.35 with the crush were obviously reduced, so the absorption energy is not much different. However, the other two sets of simulation data can be concluded that for the same thickness wall of the structural, with an increase in the density of the foam-filled aluminum, the total energy absorption decreased. 


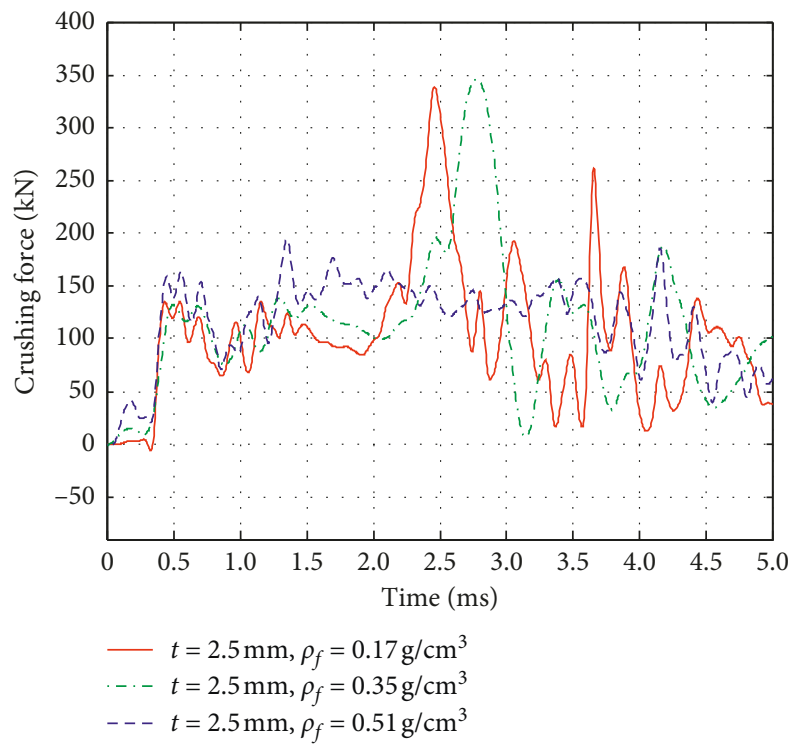

(a)

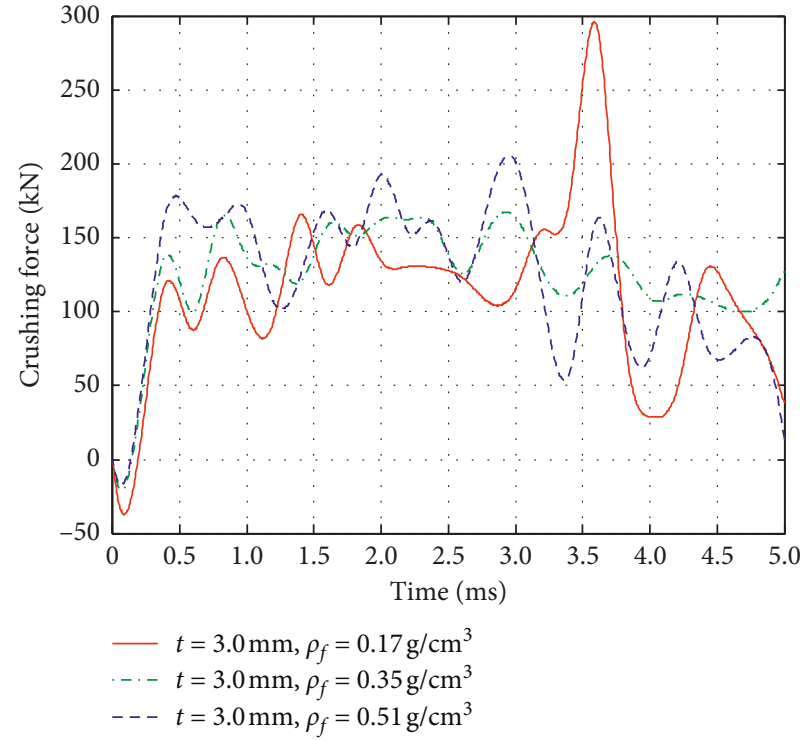

(b)

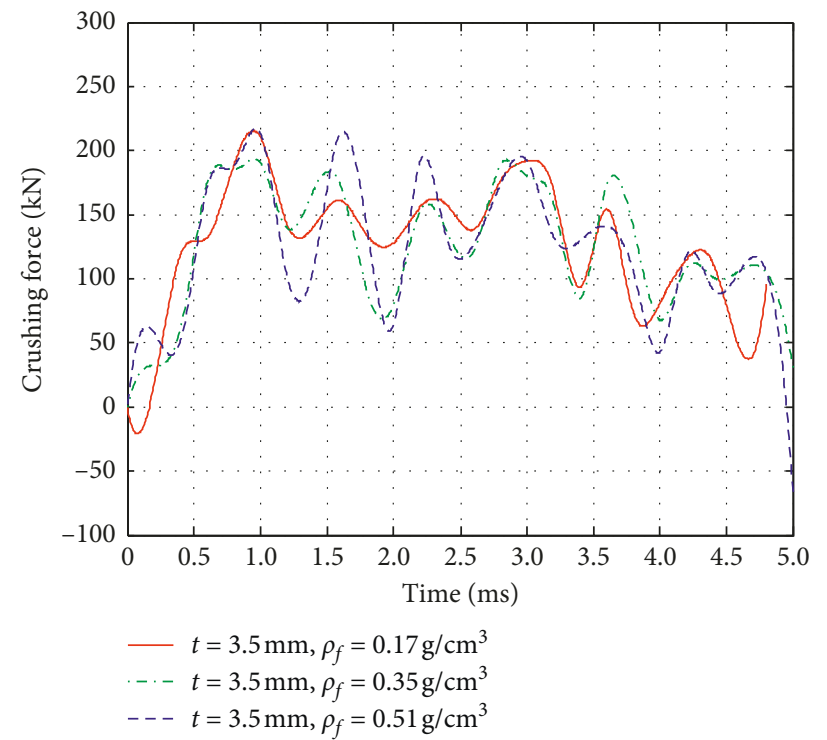

(c)

FIGURE 20: Crushing force-time curves of scientific instrumentation. Crushing force of FTS with a thickness of (a) $2.5 \mathrm{~mm}$, (b) $3.0 \mathrm{~mm}$, and (c) $3.5 \mathrm{~mm}$.

TABle 8: Loading efficiency of FTS.

\begin{tabular}{lccr}
\hline FTS & $F_{\max }(\mathrm{kN})$ & $F_{\text {avg }}(\mathrm{kN})$ & $\eta_{F}(\%)$ \\
\hline S2.5A0.17 & 337 & 136 & 40.3 \\
S2.5A0.35 & 342 & 139 & 40.6 \\
S2.5A0.51 & 198 & 151 & 76.2 \\
S3.0A0.17 & 295 & 139 & 47.1 \\
S3.0A0.35 & 206 & 168 & 81.6 \\
S3.0A0.51 & 167 & 154 & 92.2 \\
S3.5A0.17 & 210 & 156 & 74.3 \\
S3.5A0.35 & 195 & 165 & 84.6 \\
S3.5A0.51 & 205 & 174 & 84.8 \\
\hline
\end{tabular}




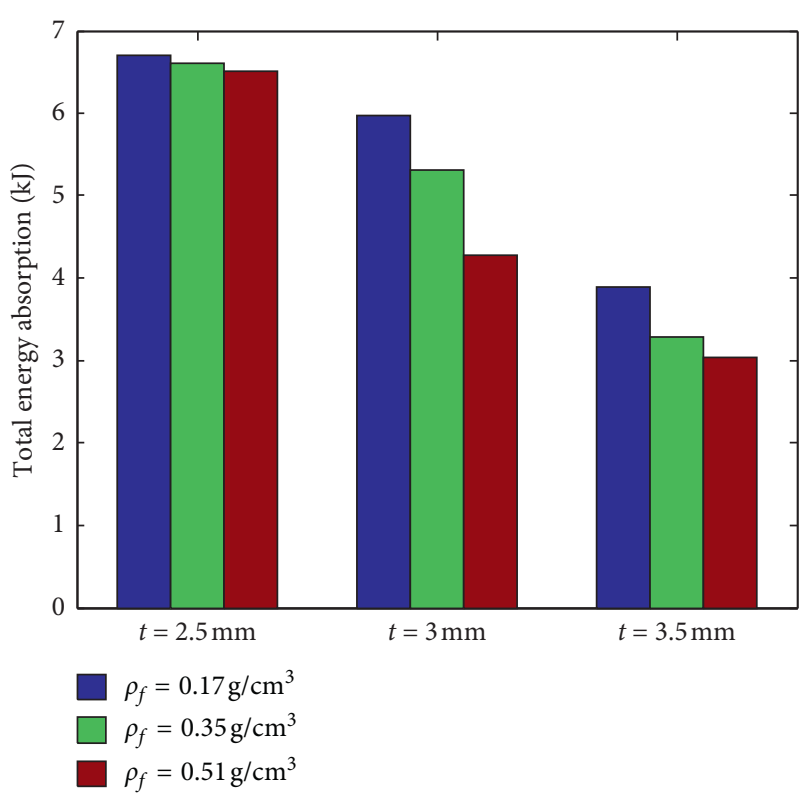

FIgURE 21: Total energy absorption of FTS.

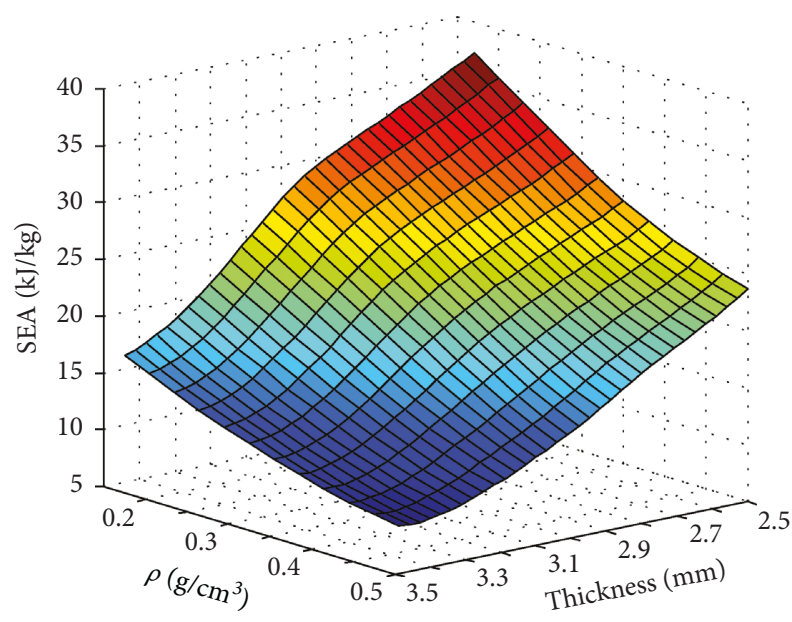

Figure 22: Response surface of SEA vs design variables.

Overall, the performance of S2.5A0.51 was superior with respect to the barrier efficiency, load efficiency, peak acceleration, peak collision energy, total energy absorption, and specific energy absorption.

\section{Conclusions}

In this study, a penetrator with a multilayer damping structure was designed, which includes rubber, polyurethane, spring and aluminum foam, a thin wall, and other damping materials. The FTS was the main vibrationdamping structure. In addition, the effects of the wall thickness and packing density on the vibration isolation and energy absorption effects of the FTS were also quantitatively studied. The conclusions of this paper are as follows.

According to the experimental results of the impact response, the penetrator finite element model was accurate. In addition, based on a comparison between the simulation results and the results of the empirical method, in addition to the theoretical analysis methods during the analysis of the penetration process of the penetrator, the analysis results of the scientific instrumentations during the penetration process were validated. The ultimate penetration depth at different landing speeds was obtained. The landing speed of the penetrator was determined to be $300 \mathrm{~m} / \mathrm{s}$, according to the detection requirements.

The vibration isolation effects of nine different FTSs were evaluated using the following six factors: the impact isolation efficiency, load efficiency, peak acceleration, peak impact force, total energy absorption, and specific energy absorption. Although the nine structures can alleviate the negative effects of the impact on the scientific instrumentation, the isolation effects were different. With respect to the evaluation criteria, the combined structure with a thin wall thickness of $2.5 \mathrm{~mm}$ and aluminum foam with a density of $0.51 \mathrm{~g} / \mathrm{cm}^{3}$ demonstrated the best performance.

The FTS can effectively reduce the overload shock of the scientific instrumentation and improve the survival probability. The shock response test cannot reach the working environment of the penetrator, and the ground test is needed. The penetration process is a thermal-mechanical coupling process, and the design of the penetrator needs to consider this part in future.

\section{Data Availability}

The data from this manuscript may be made available upon request to the authors.

\section{Conflicts of Interest}

The authors declare that there are no conflicts of interest regarding the publication of this paper.

\section{Acknowledgments}

This work was supported by the National Natural Science Foundation of China (Grant nos. 51975567 and 51505470), State Key Laboratory of Robotics (Grant no. Y7A1207301), Youth Innovation Promotion Association, CAS (Grant no. 2018237), and "JXS" innovation fund, SIA (Grant no. 20180504).

\section{References}

[1] A. Franqui, S. Seufert, and M. Okutsu, "Seismic investigation of icy crust covering subsurface oceans of Europa and Ganymede: preliminary assessment of hypothetical experiment using impactor," Acta Astronautica, vol. 155, pp. 170178, 2019.

[2] R. M. Winglee, T. Robinson, M. Danner, and J. Koch, "Cryobraking using penetrators for enhanced capabilities for the potential landing of payloads on icy solar system objects," Acta Astronautica, vol. 144, pp. 136-146, 2018.

[3] W. Lewinger, F. Comin, M. Matthews et al., "Earth analogue testing and analysis of Martian duricrust properties," Acta Astronautica, vol. 152, pp. 567-579, 2018.

[4] R. M. Saaj, C. Truitt, and R. Shibata, "High velocity penetrators used a potential means for attaining core sample for 
airless solar system objects," Acta Astronautica, vol. 137, pp. 274-286, 2017.

[5] K. Suzuki, K. Namba, and Y. Watanabe, "Visualization of high-speed impact of penetrator into icy target," Journal of Flow Control, Measurement \& Visualization, vol. 4, no. 2, pp. 56-69, 2016.

[6] T. Dirgantara, A. Jusuf, E. O. Kurniati, L. Gunawan, and I. S. Putra, "Crashworthiness analysis of foam-filled square column considering strain rate effect of the foam," ThinWalled Structures, vol. 129, pp. 365-380, 2018.

[7] S. Ebrahimi, N. Vahdatazad, and G. Liaghat, "Crashworthiness efficiency optimisation for two-directional functionally graded foam-filled tubes under axial crushing impacts," International Journal of Crashworthiness, vol. 22, no. 3, pp. 307-321, 2017.

[8] O. Mohammadiha and H. Ghariblu, "Crush behavior optimization of multi-tubes filled by functionally graded foam," Thin-Walled Structures, vol. 98, pp. 627-639, 2016.

[9] H. Fang, J. Bi, C. Zhang, M. Gutowski, E. Palta, and Q. Wang, "A constitutive model of aluminum foam for crash simulations," International Journal of Non-Linear Mechanics, vol. 90, pp. 124-136, 2017.

[10] H. Yin, G. Wen, Z. Liu, and Q. Qing, "Crashworthiness optimization design for foam-filled multi-cell thin-walled structures," Thin-Walled Structures, vol. 75, no. 75, pp. 8-17, 2014.

[11] S. Wu, G. Zheng, G. Sun, Q. Liu, G. Li, and Q. Li, “On design of multi-cell thin-wall structures for crashworthiness," International Journal of Impact Engineering, vol. 88, pp. 102117, 2016.

[12] J. G. Mantovani, G. M. Galloway, and K. Zacny, "Low force penetration of icy regolith," in Proceedings of the ASCE Earth and Space Conference, Orlando, FL, USA, April 2016.

[13] R. A. Gowen, A. Smith, A. D. Fortes et al., "Penetrators for in situ subsurface investigations of Europa," Advances in Space Research, vol. 48, no. 4, pp. 725-742, 2011.

[14] W. S. Gao, Z. H. Zhu, Z. Q. Shen et al., "Summarization of simulation test methods for spacecraft shock response spectrum," Environmental Technology, vol. 35, no. 4, pp. 60-64, 2017.

[15] Y. X. Dong, S. S. Feng, Y. D. Li et al., "Experimental study on penetration resistance of soil with low-velocity projectile," Chinese Journal of High Pressure Physics, vol. 21, no. 4, pp. 419-424, 2007.

[16] V. K. Luk and M. J. Forrestal, "Penetration into semi-infinite reinforced-concrete targets with spherical and ogival nose projectiles," International Journal of Impact Engineering, vol. 6, no. 4, pp. 291-301, 1987.

[17] M. J. Forrestal and V. K. Luk, "Penetration into soil targets," International Journal of Impact Engineering, vol. 12, no. 3, pp. 427-444, 1992.

[18] D. K. Rajak, L. A. Kumaraswamidhas, and S. Das, "Investigation of mild steel thin-wall tubes in unfilled and foamfilled triangle, square, and hexagonal cross sections under compression load," Journal of Materials Engineering and Performance, vol. 27, no. 4, pp. 1936-1944, 2018.

[19] M. D. Goel, "Deformation, energy absorption and crushing behavior of single-, double- and multi-wall foam filled square and circular tubes," Thin-Walled Structures, vol. 90, pp. 1-11, 2015.

[20] Y. Peng, H. Wu, Q. Fang, and Z. M. Gong, "Geometrical scaling effect for penetration depth of hard projectiles into concrete targets," International Journal of Impact Engineering, vol. 120, pp. 46-59, 2018.
[21] O. H. Mete, M. Yalcin, and K. Genel, "Experimental and numerical studies on the folding response of annular-rolled $\mathrm{Al}$ tube," Thin-Walled Structures, vol. 127, pp. 798-808, 2018.

[22] A. T. Barnes, K. Ravi-Chandar, S. Kyriakides, and S. Gaitanaros, "Dynamic crushing of aluminum foams: Part I-experiments," International Journal of Solids and Structures, vol. 51, no. 9, pp. 1631-1645, 2014.

[23] Z. X. Li, M. X. Zhang, and Y. C. Shi, "Experimental study on dynamic compression properties of closed-cell foamed aluminum," Vibration and Shock, vol. 36, no. 5, pp. 1-6, 2017.

[24] Q. Gao, L. M. Wang, Y. L. Wang et al., "Simulation study on oblique impact energy absorption characteristics of elliptical foam filled thin wall tube," Vibration and Shock, vol. 36, no. 2, pp. 201-206, 2017.

[25] P. Xu and T. Zhu, "Axial crushable properties of aluminumfoam filled shell in high g shock," Journal of Detection \& Control, vol. 38, no. 4, pp. 77-81, 2016.

[26] H. Yin, Y. Xiao, G. Wen, N. Gan, C. Chen, and J. Dai, "Multiobjective robust optimization of foam-filled bionic thinwalled structures," Thin-Walled Structures, vol. 109, pp. 332-343, 2016.

[27] A. Reyes, O. S. Hopperstad, T. Berstad, A. G. Hanssen, and M. Langseth, "Constitutive modeling of aluminum foam including fracture and statistical variation of density," $\mathrm{Eu}$ ropean Journal of Mechanics-A/Solids, vol. 22, no. 6, pp. $815-835,2003$.

[28] G. Sun, G. Li, S. Hou, S. Zhou, W. Li, and Q. Li, "Crashworthiness design for functionally graded foam-filled thinwalled structures," Materials Science and Engineering: A, vol. 527, no. 7-8, pp. 1911-1919, 2010.

[29] M. Gao and X. Peng, "Energy absorption characteristics study of aluminum foam-filled aluminum tubes under high g value impact," Chinese Journal of Engineering Design, vol. 22, no. 5, pp. 71-77, 2015.

[30] J. Q. Chen, X. M. Zhou, J. Q. Rao et al., "A research on the impact energy absorption characteristics and optimization of thin-walled structure of vehicle front rail," Automotive Engineering, vol. 32, no. 6, pp. 486-492, 2010.

[31] P. Zhang, Z. Wang, and L. Zhao, "Dynamic crushing behavior of open-cell aluminum foam with negative Poisson's ratio," Applied Physics A, vol. 123, no. 5, p. 321, 2017. 


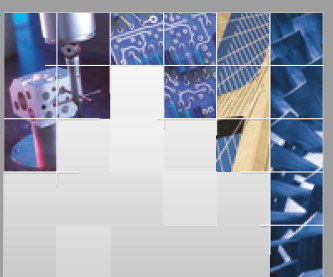

\section{Enfincering}
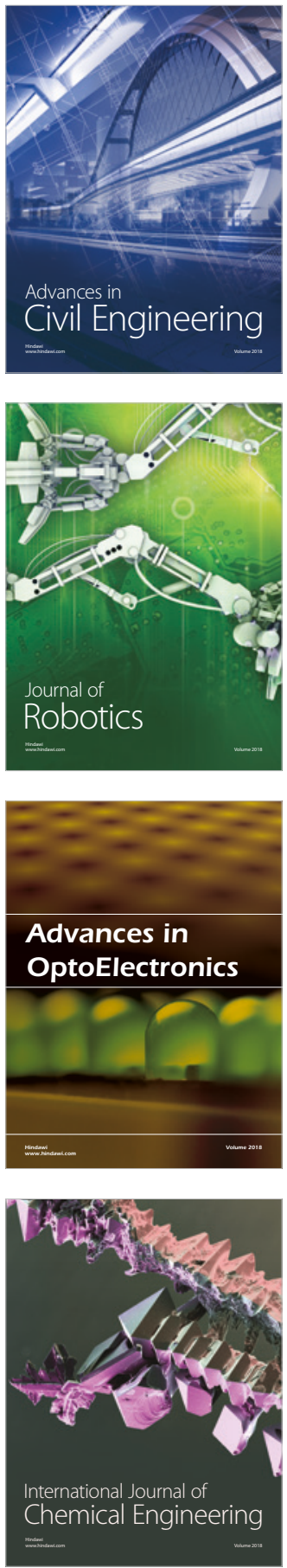

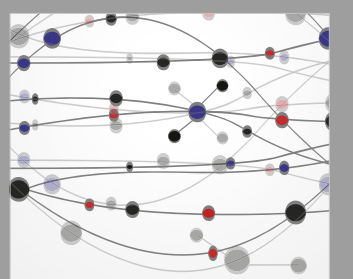

\section{Rotating \\ Machinery}

The Scientific World Journal

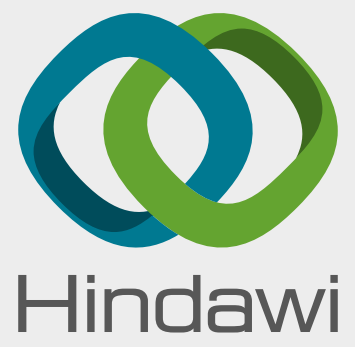

Submit your manuscripts at

www.hindawi.com
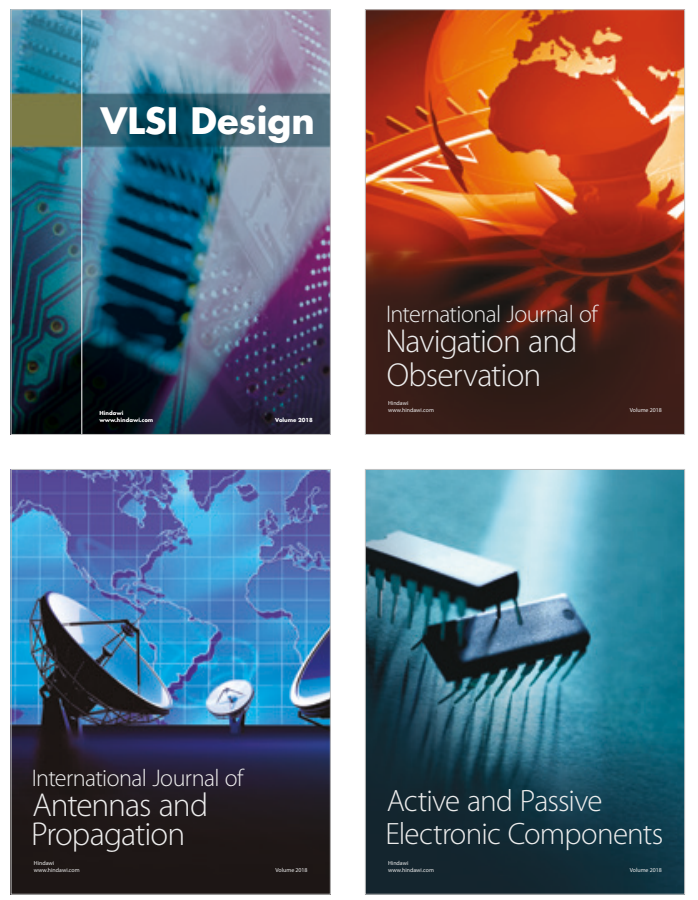
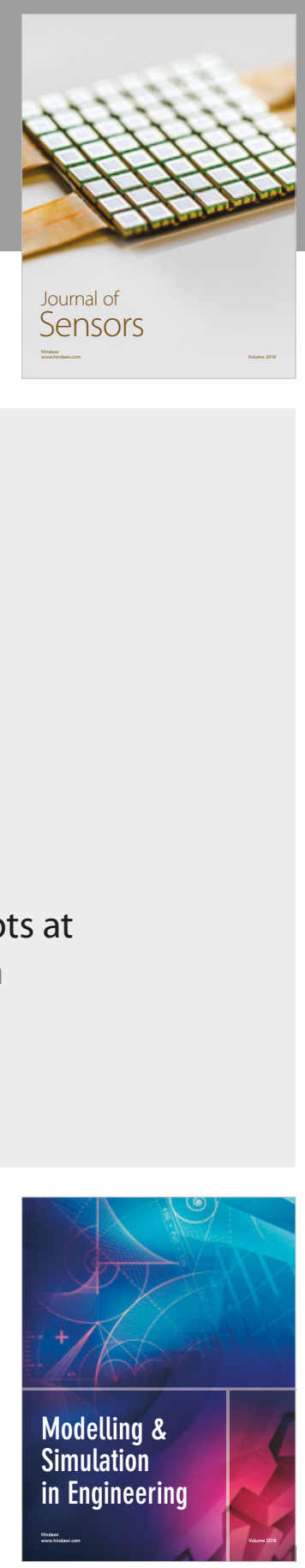

\section{Advances \\ Multimedia}
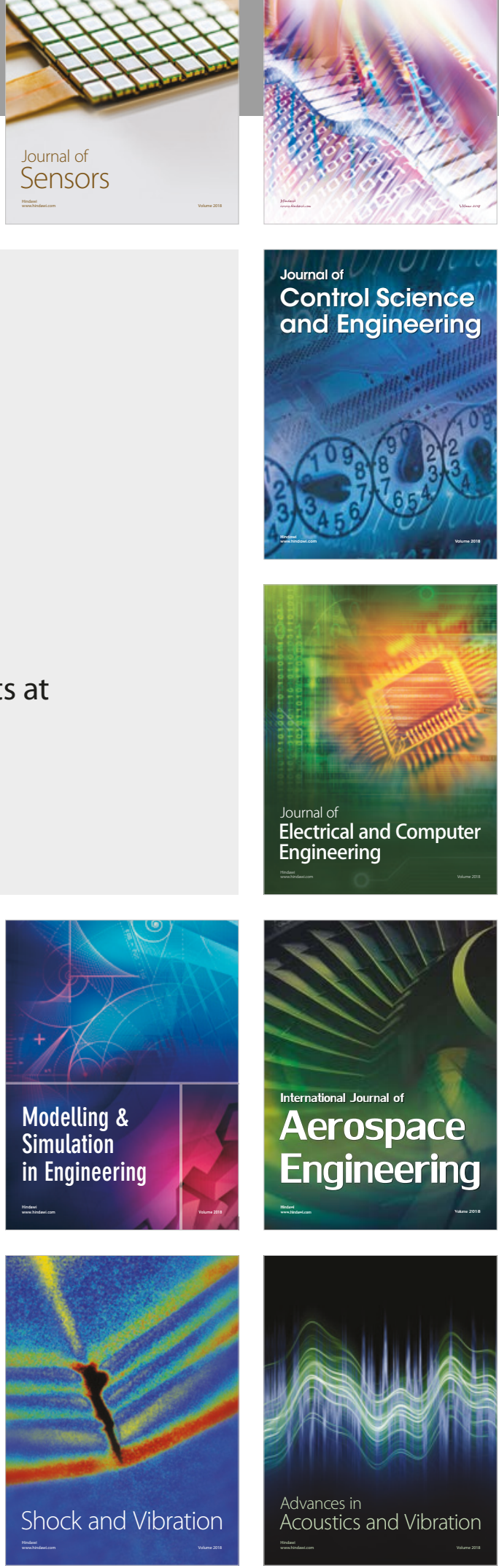